\title{
How to PROMOte R\&D-BASED GROWTH? PUBLIC EDUCATION EXPENDITURE ON SCIENTISTS AND ENGINEERS VERSUS R\&D SUBSIDIES
}

\author{
VOLKER GROSSMANN \\ CESIFO WorkING PAPER NO. 1225 \\ CATEgORY 1: Public FinANCE \\ JUNE 2004
}
An electronic version of the paper may be downloaded
- from the SSRN website:
www.SSRN.com
- from the CESifo website:
www.CESifo.de




\title{
How to Promote R\&D-based Growth? Public Education Expenditure on Scientists and Engineers versus R\&D Subsidies
}

\begin{abstract}
Empirical evidence suggests that positive externalities from R\&D exceed negative ones. According to conventional wisdom, this calls for R\&D subsidies. This paper develops a quality-ladder growth model with overlapping generations which evaluates the positive and normative implications of R\&D subsidies and compares them with the effects of public education policy to promote R\&D. Unlike standard growth models, the proposed framework accounts for the specificity of science and engineering (S\&E) skills, where individuals endogenously choose the type of education, and allows for heterogeneity in individual ability. Although intertemporal knowledge spillovers are hypothesized and negative R\&D externalities are absent, the analysis shows somewhat surprisingly that R\&D subsidies may be detrimental to both productivity growth and welfare, in contrast to publicly provided education targeted to S\&E skills. Finally, the optimal structure of public education spending on different skills is examined.
\end{abstract}

JEL Classification: H20, O31, O38, O41.

Keywords: education policy, endogenous growth, R\&D subsidies, scientists and engineers, skill specificity.

Volker Grossmann

Socioeconomic Institute

University of Zurich

Zürichbergstr. 14

CH-8032 Zürich

Switzerland

volker.grossmann@wwi.unizh.ch 


\section{Introduction}

R\&D-based models of economic growth have substantially contributed to our understanding of the interplay between firms' incentives to invest in $\mathrm{R} \& \mathrm{D}$, economic growth and welfare. It has been pointed out that R\&D may have positive as well as negative externalities, leaving the question whether there is over- or underinvestment in $\mathrm{R} \& \mathrm{D}$ in decentralized equilibrium (compared to the social optimum) theoretically ambiguous. ${ }^{1}$ By trying to shed light into this ambiguity, both empirical evidence as well as calibration exercises strongly suggest that the social return to R\&D significantly exceeds the private return to R\&D (e.g., Jones and Williams, 1998, 2000; Alvarez-Pelaez and Groth, 2003). For instance, Jones and Williams (1998), by linking R\&D-based growth models to the productivity literature, argue that "[a] conservative estimate indicates that optimal investment in research is more than two to four times actual investment" (p.1134).

Such evidence has alarmed policy makers. For instance, the Barcelona European Council 2002 has brought consensus among EU members "to increase the average research investment level from $1.9 \%$ of GDP today to $3 \%$ of GDP by 2010, of which $2 / 3$ should be funded by the private sector" (COM, 2003, p.3). In particular, the European Commission seems to be ready to provide firms with more financial incentives to invest in $R \& D$, arguing that "[p]ublic support is justified by the recognised failure of the market to induce business investment in research at an optimal level" (COM, 2003, p.19). However, as pointed out by Romer (2000) in his informal discussion about U.S. government policies to encourage R\&D spending, "[f]ew participants in

\footnotetext{
${ }^{1}$ At least four externalities have been identified by the literature (see e.g. Jones, 2003). First, innovators do not take into account that their R\&D output may enhance capabilities of future innovators, which has been called "standing on shoulders" or "intertemporal knowledge spillover" effect, introduced by Romer (1990). Second, the equilibrium mark up which innovators can charge for a new design may not coincide with the consumer surplus created by a new good, i.e., innovating firms can appropriate only part of the surplus (Jones and Williams, 2000). These two distortions promote underinvestment in $\mathrm{R} \& \mathrm{D}$ activities. Third, when new goods replace older goods, gains from past innovating effort is lost. This "business-stealing" effect, introduced by Grossman and Helpman (1991) and Aghion and Howitt (1992), serves as a negative externality of R\&D investments. Finally, overinvestment in R\&D is also promoted by patent races, in which different firms work on similar R\&D projects in the hope to be the first to be assigned a patent for their innovation ("duplication externality").
} 
[the political debate surrounding demand-subsidy policies] seem to have considered the broad range of alternative programs that could be considered" (pp.5-6). So the question is not whether public policy should promote R\&D but how to do it.

This paper contributes to this debate by comparing positive and normative effects of two alternative measures to foster R\&D-based growth: (demand-side) R\&D subsidies and (supply-side) publicly provided education for scientists and engineers. The theoretical innovation of the paper is to develop a quality-ladder growth model with overlapping generations which rests on three elements. First, the model accounts for the fact that R\&D occupations require specific skills, which may differ substantially from skills applicable in non-R\&D tasks. For instance, scientists or engineers are not necessarily capable to perform (skill-intensive) non-R\&D activities like bookkeeping, machine operating or providing legal services, and vice versa. Second, and related to this, individuals endogenously choose which skill type to acquire, science and engineering ( $\mathrm{S} \& \mathrm{E}$ ) skills in order to be employed in R\&D jobs, skills applicable for production-related tasks, or to remain unskilled. That is, the analysis distinguishes between skills which are crucial for improving productivity growth and those applicable in the process of producing consumption goods. Moreover, it allows for public education expenditure targeted to both types of skills. Third, individuals are heterogeneous in their ability to perform R\&D jobs when choosing to acquire S\&E skills, which reflects the notion that R\&D activities require extraordinary talent.

The analysis shows that by accounting for these important features substantially alters the positive and normative implications of R\&D subsidies drawn from standard models. $^{2}$ To highlight this point, the framework hypothesizes that intertemporal knowledge spillovers are the only (unambiguously positive) externality from R\&D. Clearly, in standard models of endogenous technological change which do not

\footnotetext{
${ }^{2}$ Growth theory has successfully integrated models in which R\&D and human capital accumulation are engines of growth by emphasizing the complementarity between these two factors for the process of development (e.g., Redding, 1996; Arnold, 1998; Funke and Strulik, 2000; Strulik, 2004). However, to the best of my knowledge, the implications of allowing for an endogenous formation of specific S\&E skills for R\&D-based growth have not been examined yet.
} 
allow for skill specificity and educational choice, this calls for positive R\&D subsidies to firms in order to induce a reallocation of labor towards R\&D activity. This result critically depends on the assumption, however, that the (high-skilled) labor force is capable to perform both $\mathrm{R} \& \mathrm{D}$ and production activities without having to adjust to a change in occupation. One obvious drawback of this assumption is that labor supply of scientists and engineers is rather inelastic in the short-run, i.e., R\&D subsidies are absorbed by rising factor prices for R\&D inputs, as discussed in Romer (2000), among others. This paper not only confirms this view but also shows that even by accounting for long-run supply responses, earnings of scientists and engineers rise unambiguously. This result is driven by the heterogeneity of individuals in ability. It is consistent with empirical evidence by Goolsbee (1998), who finds that a 10 percent increase in government spending on R\&D affects both income and hourly wages of scientists and engineers by 3 percent even in the longer run. Moreover, the proposed theory suggests that $R \& D$ subsidies may reduce effective aggregate supply of S\&E skills, and may be detrimental to both productivity growth and welfare. That is, R\&D policy targeted to demand may not foster innovative activity when the specificity and endogeneity of the supply of S\&E skills is taken into account.

Fortunately, the analysis suggests a sensible and straightforward alternative to promote R\&D-based growth: to target public R\&D spending directly to the supply of skills. First, a promotion of extraordinary S\&E talent does not affect the distribution of earnings, which is in sharp contrast to the result that R\&D subsidies to firms foster earnings inequality. Moreover, and also in contrast to R\&D subsidies, education spending on S\&E skills unambiguously raise productivity growth. Finally, the normative analysis shows that the socially optimal structure of public education expenditure to different skills depends on the interaction between the relative effectiveness of the education system across skills and the effectiveness of private-sector R\&D spending relative to the output elasticity of production skills.

The paper is organized as follows. Section 2 presents the structure of the model. Section 3 derives both the short-run equilibrium and the equilibrium with full educational adjustment to public policy measures (long-run). Section 4 studies the 
socially optimal policy design with respect to both $R \& D$ subsidies and the structure of public education expenditure towards skills applicable in R\&D and production activities, respectively. Section 5 discusses the results and concludes. All proofs are relegated to an appendix.

\section{Basic Model}

Consider the following overlapping-generations economy, where each generation is populated by $L$ individuals.

\subsection{Individuals}

Individuals live for two periods. In the first period of life, individuals live with their parents and decide (rationally and under perfect information) whether to specialize in S\&E skills (i.e., to work as scientist or engineer), to acquire skills applicable in more routinized production processes, or to remain unskilled. Individuals have a unit time endowment in the first period of life, devoted entirely to the acquisition of skills and leisure. Acquiring $\mathrm{S} \& \mathrm{E}$ skills is necessary to perform $\mathrm{R} \& \mathrm{D}$ tasks and requires $z^{R} \in(0,1)$ units of time, whereas acquiring production skills requires $z^{S} \in(0,1)$ units of time. In the second period of life (adulthood), individuals supply their skills inelastically to a perfect labor market. After specializing in, e.g., S\&E skills, an individual cannot work in routinized production, and vice versa. ${ }^{3}$ This reflects the notion that, say, a lawyer or bookkeeper cannot do research on software and an IT specialist cannot be employed as lawyer or bookkeeper. Individuals differ in the ability to perform R\&D tasks after having acquired S\&E skills, denoted by $a$. As will be specified in section 2.3, this is reflected by differences in efficiency units of S\&E skills possessed by R\&D workers, after incurring $z^{R}$ units of time. In order to focus the analysis on an ability type which is relevant for knowledge spillovers and

\footnotetext{
${ }^{3}$ In principle, the set up allows for the possibility that either type of skilled worker can be employed (in the same occupations) as unskilled workers. However, as will become apparent, this cannot be an equilibrium outcome.
} 
growth, this is the only source of individual heterogeneity in the model. ${ }^{4}$

Intertemporal preferences of an individual $i$ born in $t-1$ (i.e., a member $i$ of generation $t-1)$ are defined over leisure time in the first period of life, $d_{t-1}(i)$, and consumption during adulthood (e.g., Glomm and Ravikumar, 2003). The utility function is specified as

$$
U_{t-1}(i)=\ln d_{t-1}(i)+\ln C_{t}(i)
$$

where

$$
C_{t}(i)=\left(\int_{0}^{n_{t}}\left(\tilde{x}_{t}(i, j)\right)^{\frac{\sigma-1}{\sigma}} d j\right)^{\frac{\sigma}{\sigma-1}}
$$

$\sigma>1$, is an index of differentiated goods (Dixit and Stiglitz, 1977); $\tilde{x}_{t}(i, j)$ denotes the quantity of good $j \in\left[0, n_{t}\right]$ consumed by member $i$ of generation $t-1$ in period $t$. The measure $n_{t}$ is referred to as the "number of products" in $t$. Note that, according to (2), individuals "love variety" in the sense that for any given total consumption of differentiated goods, $n \tilde{x}$, utility increases with $n$.

\section{$2.2 \quad$ Firms}

Each producer manufactures one variety of the differentiated goods in monopolistic competition. Firms have the following simple Cobb-Douglas production technology:

$$
x_{t}(j)=A_{t}(j) l_{t}^{S}(j)^{\alpha} l_{t}^{U}(j)^{1-\alpha}
$$

$0<\alpha<1 . l_{t}^{S}(j)$ and $l_{t}^{U}(j)$ denote efficiency units of skilled and unskilled productionrelated labor employed in firm $j$ at date $t$, respectively, whereas $x_{t}(j)$ and $A_{t}(j)$ are output and total factor productivity of firm $j$ in $t$.

\footnotetext{
${ }^{4}$ This is not to deny that, for instance, there are productivity differences among students graduating in law, but these skills do not seem to foster growth. For instance, Murphy, Shleifer and Vishny (1991) present empirical cross-country evidence that the fraction of students in engineering fields (around 10 percent on average in their sample) is positively related to growth, whereas the fraction of law students (around 9 percent on average) even adversely affects growth.
} 
In each period $t$, firm $j$ can affect productivity $A_{t}(j)$ by employing scientists and engineers. ${ }^{5}$ In line with growth theory based on in-house R\&D (e.g., Young, 1998) and the IO literature on innovation activities (e.g., Sutton, 1998), R\&D outlays are (endogenous) sunk costs for firms. Productivity $A_{t}(j)$ of firm $j$ in any period $t \geq 0$ evolves according to

$$
A_{t}(j)=\left\{\begin{array}{cl}
\bar{S}_{t-1} h\left(l_{t}^{R}(j)\right) & \text { if } h\left(l_{t}^{R}(j)\right) \geq 1 \\
\bar{S}_{t-1} & \text { otherwise }
\end{array}\right.
$$

where $l_{t}^{R}(j)$ denotes the efficiency units of R\&D labor investments of firm $j$ in period $t$ and $h(\cdot)$ is an increasing function. ${ }^{6}$ For simplicity, $h(\cdot)$ is specified as

$$
h\left(l^{R}\right)=\left(l^{R}\right)^{\gamma}
$$

where $\gamma>0$ measures the effectiveness of R\&D. Moreover,

$$
\bar{S}_{t-1}=\frac{\bar{S}_{t-2}}{\left(n_{t-1}\right)^{\varepsilon}} \int_{0}^{n_{t-1}} h\left(l_{t-1}^{R}(j)\right) d j
$$

$0<\varepsilon \leq 1$, reflects an intertemporal spillover effect from previous investments of firms in $\mathrm{R} \& \mathrm{D}, t \geq 1$, where $\bar{S}_{-1}>0$ is historically given. ${ }^{7}$ Note that, according to (6), if each firm chooses the same R\&D investment, i.e., if $l_{t-1}^{R}(j)=l_{t-1}^{R}$ for all $j$ (which will be the case in equilibrium), then $\bar{S}_{t-1}=\bar{S}_{t-2}\left(n_{t-1}\right)^{1-\varepsilon} h\left(l_{t-1}^{R}\right)$. Thus,

\footnotetext{
${ }^{5}$ An alternative formulation is that firms have to incur $\mathrm{R} \& \mathrm{D}$ expenditure one period in advance of production (financed by borrowing), like in the (discrete-time) infinite-horizon growth model of Young (1998). (See also Grossmann, 2003.) However, this assumption seems to be less plausible in an OLG model. Rather, for simplicity (since irrelevant for the main arguments of this paper), the analysis abstracts from savings and asset markets.

${ }^{6}$ Alternatively to the analysis of productivity-enhancing technological progress, one could allow for improvements in the quality of goods. Formally, replace $(2)$ by $C_{t}(i)=$ $\left(\int_{0}^{n_{t}}\left(q_{t}(j) x_{t}(i, j)\right)^{\frac{\sigma-1}{\sigma}} d i\right)^{\frac{\sigma}{\sigma-1}}$, where $q_{t}(j)$ is perceived quality of good $j$ in $t$, and let $A_{t}(j)=A>0$ for all $j$ and $t$. Moreover, let quality $q_{t}(j)$, rather than $A_{t}(j)$, evolve according to the right-hand side of (4). It is easy to show that, under these modifications, all results in this paper remain exactly the same.

${ }^{7}$ Regarding intellectual property rights, (4) and (6) imply that innovations are proprietary knowledge for one period only.
} 
if $\varepsilon=1$, then $\bar{S}_{t-1}$ is ceteris paribus independent on the number of firms, $n_{t-1}$. This special case reflects the notion that innovations of firms are "equivalent" in the sense that firms come up with similar solutions to similar problems at the same time, having similar access to the state-of-the-art technologies (Young, 1998). ${ }^{8}$ In contrast, allowing for $\varepsilon<1$ implies that the number of innovating firms in symmetric equilibrium positively affects future productivity growth.

There is free entry of firms into the economy, with a large number of potential entrants. At all times, firms have to incur standard fixed cost $f>0$ in terms of unskilled labor. ${ }^{9}$ Since $f$ has to be incurred each period and the intertemporal spillover effect cannot be appropriated by firms, the length of the planning horizon of firms is exactly one period (Young, 1998).

\subsection{Educational Production and Government Spending}

To focus on the role of public education spending, educational production solely depends on public expenditure for either type of education, development of S\&E skills or production skills, respectively. ${ }^{10}$ Denote public expenditure levels for S\&E skills and production skills of generation $t-1$ by $G_{t-1}^{R}$ and $G_{t-1}^{S}$, respectively, and the population share of either type of worker in period $t$ (i.e., one period after receiving education) by $s_{t}^{R}$ and $s_{t}^{S}$, respectively. Moreover, let $s_{t}^{U}=1-s_{t}^{R}-s_{t}^{S}$ be the population share of unskilled workers in $t$. The spending levels per student are given by

$$
g_{t-1}^{R}=\frac{G_{t-1}^{R}}{s_{t}^{R} L} \text { and } g_{t-1}^{S}=\frac{G_{t-1}^{S}}{s_{t}^{S} L},
$$

\footnotetext{
${ }^{8}$ Consequently, as will become apparent, the specification $\varepsilon=1$ eliminates the scale effect from population size $L$ in the economy's growth rate.

${ }^{9}$ The main results from the analysis are unaffected if production would also require a fixed staff of skilled, non-R\&D workers. However, the additional analytical complexity would be substantial, and is avoided here for the sake of simplicity.

${ }^{10}$ It is straightforward to allow for certain forms of private human capital investments as well without affecting the main results of this study. One standard justification for public finance of education is the incapability of individuals to borrow for educational purposes. As a matter of fact, public education systems are particularly prevalent in Continental Europe.
} 
respectively. Denote the set of individuals (of generation $t-1$ ) who supply S\&E skills and production skills in period $t$ by $\mathcal{R}_{t}$ and $\mathcal{S}_{t}$, respectively. (Thus, $s_{t}^{R} L=\int_{\mathcal{R}_{t}} d i$ and $s_{t}^{S} L=\int_{\mathcal{S}_{t}} d i$.) An individual $i \in \mathcal{R}_{t}$ with ability $a(i)$ acquires

$$
e_{t}^{R}(a(i))=a(i) \xi^{R}\left(g_{t-1}^{R}\right)^{\beta^{R}}
$$

efficiency units of R\&D labor. For simplicity, suppose ability $a$ is uniformly distributed on the unit interval, i.e., $a \sim$ uniform $\{0,1\}$. Each individual $i \in \mathcal{S}_{t}$ obtains

$$
e_{t}^{S}=\xi^{S}\left(g_{t-1}^{S}\right)^{\beta^{S}}
$$

efficiency units of production skills; $\xi^{k}>0,0<\beta^{k} \leq 1, k=R, S$. (Recall that individuals only differ in their ability to perform R\&D tasks.) Note that individual efficiency units of labor depend on per capita spending levels for education $\left(g^{R}\right.$, $g^{S}$ ), which reflects that publicly provided education is a rival good. Also note that educational production is subject to diminishing returns when $\beta^{R}, \beta^{S}<1$. If remaining unskilled, an individual owns one unit of unskilled labor $\left(e_{t}^{U}=1\right)$.

Recall that individuals inelastically supply their efficiency units during working life. Let $w_{t}^{R}$ and $w_{t}^{S}$ denote the wage rate per efficiency unit of S\&E skills and production skills at date $t$, respectively. Unskilled labor is chosen as numeraire $\left(w_{t}^{U}=1\right)$. Using (8) and (9), the nominal income (or earnings) level of a member $i$ of generation $t-1$ (with ability $a(i)$ ), conditional on her educational choice, is thus given by

$$
I_{t}(i)=\left\{\begin{array}{c}
w_{t}^{R} a(i) \xi^{R}\left(g_{t-1}^{R}\right)^{\beta^{R}} \equiv I_{t}^{R}(a(i)) \text { if } i \in \mathcal{R}_{t} \\
w_{t}^{S} \xi^{S}\left(g_{t-1}^{S}\right)^{\beta^{S}} \equiv I_{t}^{S} \text { if } i \in \mathcal{S}_{t} \\
1 \\
\text { otherwise }
\end{array}\right.
$$

Let $L_{t}^{R}, L_{t}^{S}$ and $L_{t}^{U}$ denote aggregate supply of efficiency units of R\&D labor, skilled production labor, and unskilled labor in $t$, respectively, where $L_{0}^{R}, L_{0}^{S}$ and $L_{0}^{U}$ are historically given.

At each $t$, besides financing education, the government may subsidize $R \& D$ 
spending of firms at rate $\mu_{t} \in[0,1)$. For any $t \geq 1, \mu_{t}$ is announced at least one period in advance, which implies that members of generation $t-1$ take $\mu_{t}$ into account when choosing among educational fields. Both education expenditure and $\mathrm{R} \& \mathrm{D}$ subsidies are financed by a proportional income tax on workers, where $\tau_{t} \in[0,1)$ denotes the tax rate at date $t$. The government budget is balanced each period.

\section{Equilibrium Analysis}

\subsection{Equilibrium for Given Educational Choice}

According to (1) and (2), utility maximization implies that the demand function faced by firm $j$ in period $t$ is given by ${ }^{11}$

$$
x_{t}^{D}(j)=\frac{E_{t} p_{t}(j)^{-\sigma}}{P_{t}^{1-\sigma}},
$$

where $E_{t}=\left(1-\tau_{t}\right)\left(w_{t}^{R} L_{t}^{R}+w_{t}^{S} L_{t}^{R}+L_{t}^{U}\right)$ is aggregate (nominal) expenditure for final consumption goods (which equals aggregate disposable income of generation $t-1$ during adulthood $), p_{t}(j)$ is the price of good $j$, and

$$
P_{t} \equiv\left(\int_{0}^{n_{t}} p_{t}(j)^{1-\sigma} d j\right)^{\frac{1}{1-\sigma}}
$$

is the price index in $t$. It is easy to verify that $P_{t}$ is defined such that

$$
C_{t}(i)=\frac{\left(1-\tau_{t}\right) I_{t}(i)}{P_{t}}
$$

i.e., for any individual $i$, the consumption index $C_{t}(i)$ equals "real" disposable income of $i$ at date $t$.

\footnotetext{
${ }^{11}$ Solving $\max _{\left\{\tilde{x}_{t}(i, j)\right\}_{j \in\left[0, n_{t}\right]}}\left(\int_{0}^{n_{t}}\left(\tilde{x}_{t}(i, j)\right)^{\frac{\sigma-1}{\sigma}} d i\right)^{\frac{\sigma}{\sigma-1}}$ s.t. $\left.\left.\int_{0}^{n_{t}} p_{t}(i, j)\right) x_{t}(i, j)\right) d j=I_{t}(i)$ yields demand functions $\left.\tilde{x}_{t}^{D}(i, j)\right)=\left(1-\tau_{t}\right) I_{t}(i) p_{t}(j)^{-\sigma} / \int_{0}^{n_{t}} p_{t}(j)^{1-\sigma} d j, j \in\left[0, n_{t}\right]$. Integrating over all $i$ and observing (12) confirms (11).
} 
Using (11), output prices are set according to the well-known formula

$$
p_{t}(j)=\frac{\sigma}{\sigma-1} c_{t}(j)
$$

$t \geq 0$ (Dixit and Stiglitz, 1977), where $c_{t}(j)$ denotes marginal production cost, which, according to (3) (and $w_{t}^{U}=1$ ), are given by

$$
c_{t}(j)=\frac{\alpha^{-\alpha}(1-\alpha)^{-(1-\alpha)}\left(w_{t}^{S}\right)^{\alpha}}{A_{t}(j)} .
$$

Note that profits of firm $j$ in $t$ can be written as

$$
\pi_{t}(j)=\left(p_{t}(j)-c_{t}(j)\right) x_{t}^{D}(j)-\left(1-\mu_{t}\right) w_{t}^{R} l_{t}^{R}(j)-f .
$$

Regarding the choice of effective R\&D labor, $l_{t}^{R}(j)$, the analysis exclusively focusses on $h\left(l_{t}^{R}(j)\right) \geq 1$ (see (4)). Thus, using (4), (11), (14), (15) and (16), firm $j$ solves

$$
\max _{l_{t}^{R}(j)}\left\{\left(\frac{P_{t} \bar{S}_{t-1} h\left(l_{t}^{R}(j)\right)}{\left(w_{t}^{S}\right)^{\alpha}}\right)^{\sigma-1} \Gamma E_{t}-\left(1-\mu_{t}\right) w_{t}^{R} l_{t}^{R}(j)-f\right\}
$$

where $\Gamma \equiv \alpha^{\alpha(\sigma-1)}(1-\alpha)^{(1-\alpha)(\sigma-1)}(\sigma-1)^{\sigma-1} / \sigma^{\sigma}>0, t \geq 0$. Note that firms take $\mu_{t}$, $w_{t}^{S}, w_{t}^{R}, E_{t}$ and $P_{t}$ as given. Hence, the first-order condition for the optimal choice of $R \& D$ labor reads

$$
\left(\frac{P_{t} \bar{S}_{t-1}}{\left(w_{t}^{S}\right)^{\alpha}}\right)^{\sigma-1} h\left(l_{t}^{R}(j)\right)^{\sigma-2} h^{\prime}\left(l_{t}^{R}(j)\right) \Gamma E_{t}=\left(1-\mu_{t}\right) w_{t}^{R} .
$$

Condition (18) says that the marginal benefit of an increase in R\&D labor in $t$ must equal its marginal cost. Note that the latter is decreasing in $\mu_{t}$, all other things equal, implying that demand for scientists and engineers is increasing in the R\&D subsidy rate $\mu_{t}$. Using (5), it is easy to show that for the second-order condition for a profit maximum to hold, $1>\gamma(\sigma-1)$ is required, which is assumed throughout the paper. Moreover, note that (18) implies $l_{t}^{R}(j)=l_{t}^{R}$, and thus, according to (4), $A_{t}(j)=A_{t}$ for all $j$. It is easy to see that this also implies $c_{t}(j)=c_{t}, p_{t}(j)=p_{t}, x_{t}^{D}(j)=x_{t}^{D}$, 
$l_{t}^{S}(j)=l_{t}^{S}$ and $l_{t}^{U}(j)=l_{t}^{U}$ for all $j$, i.e., there is symmetry in equilibrium. Thus, besides conditions (14) and (18) from profit maximization, the following equilibrium conditions must hold for any $t \geq 0$ :

(E1) $x_{t}^{D}=A_{t}\left(l_{t}^{S}\right)^{\alpha}\left(l_{t}^{U}\right)^{1-\alpha}$ (goods market equilibrium),

(E2) $n_{t}\left(l_{t}^{U}+f\right)=L_{t}^{U}, n_{t} l_{t}^{R}=L_{t}^{R}$, and $n_{t} l_{t}^{S}=L_{t}^{S}$ (labor market clearing),

(E3) $\pi_{t}(j)=0$ for all $j \in\left[0, n_{t}\right]$, i.e., $\left(p_{t}-c_{t}\right) x_{t}^{D}=\left(1-\mu_{t}\right) w_{t}^{R} l_{t}^{R}+f$ (free entry).

For given educational choices, the following equilibrium income levels result. (All results are proven in Appendix.)

Lemma 1. For any $t \geq 1$, the following holds in equilibrium for given $\mathcal{R}_{t}$ and $\mathcal{S}_{t} \cdot{ }^{12}$

$$
\begin{aligned}
I_{t}^{R}(a(i)) & =\frac{a(i) \gamma(\sigma-1) L\left(1-s_{t}^{R}-s_{t}^{S}\right)}{\Xi\left(1-\mu_{t}\right) \int_{\mathcal{R}_{t}} a(i) d i}, \\
I_{t}^{S} & =\frac{\alpha(\sigma-1)\left(1-s_{t}^{R}-s_{t}^{S}\right)}{\Xi s_{t}^{S}}
\end{aligned}
$$

where $\Xi \equiv 1+(1-\alpha-\gamma)(\sigma-1)>0 .{ }^{13}$ Thus, for given educational choices, $I_{t}^{R}(a(i))$ is increasing in $\mu_{t}$, whereas $I_{t}^{S}$ is independent of $\mu_{t}$. Both $I_{t}^{R}(a(i))$ and $I_{t}^{S}$ are independent of $G_{t-1}^{k}, k=R, S$.

For given educational choices, an increase in government spending on education, $G_{t-1}^{R}$ or $G_{t-1}^{S}$, has two opposing effects on income levels of workers with S\&E skills and production skills from generation $t-1$, respectively. First, observing (7), efficiency units per worker are enhanced, according to (8) and (9), respectively. This raises income levels of skilled workers, according to (10), when holding wage rates per efficiency unit, $w_{t}^{R}$ and $w_{t}^{S}$, respectively, constant. Second, however, if $G_{t-1}^{k}$ increases, wage rate $w_{t}^{k}$ declines, $k=R, S$, due to an increase in the effective aggregate supply of the respective type of skills, $L_{t}^{R}$. Both effects exactly cancel under the specifications of the model. In contrast, an increase in the R\&D subsidy rate

\footnotetext{
${ }^{12}$ Thus, $s_{t}^{R}$ and $s_{t}^{S}$ are given.

${ }^{13} \Xi>0$ is implied by $\alpha<1$ together with assumption $1>\gamma(\sigma-1)$.
} 
in period $t, \mu_{t}$, raises demand of firms for $\mathrm{S} \& \mathrm{E}$ skills in $t$. For given educational choices, this unambiguously raises wage rate $w_{t}^{R}$, and thus, raises income levels of scientists and engineers, according to (10).

Before analyzing the implications of Lemma 1 for educational choices, consider the short-run impact of an increase in R\&D subsidies, i.e., the impact of an increase in $\mu_{0}$ on the equilibrium in period $0 .{ }^{14}\left(G_{0}^{R}\right.$ and $G_{0}^{S}$ do not affect the short-run equilibrium since skills are supplied by individuals one period after receiving education.)

Proposition 1. (Short-run effects). An increase in $\mu_{0}$ raises $w_{0}^{R}$, and has no impact on $n_{0}, w_{0}^{S}$ and $A_{0}$ in equilibrium.

Proposition 1 implies that an increase in R\&D subsidies to firms, which is unanticipated by individuals, merely serves as a windfall gain for individuals who happen to possess S\&E skills. Thus, inequality across educational groups is raised, without affecting net wage costs of firms for R\&D activity at all. Consequently, product variety, marginal production costs and productivity (i.e., inventive activity) remain unchanged, respectively. This result is an implication of the assumption that S\&E skills need time to develop, i.e., are in inelastic supply in the short-run, as has been argued (informally) in the previous literature (Goolsbee, 1998; Romer, 2000).

However, what has not been explored yet in the theoretical literature are the long-run effects and policy implications associated with educational decisions under skill specificity and heterogeneity in ability. This is done next.

\subsection{Equilibrium with Endogenous Educational Choice}

Substituting (13) into (1), using (10), and observing time requirements $z^{R}$ and $z^{S}$ for the acquisition of skills, indirect life-time utility of individual $i$ from generation

\footnotetext{
${ }^{14}$ Recall that, for the initially adult generation, efficiency units of all skill types are exogenously given. Thus, the short-run analysis is equivalent to that of a policy change which is not anticipated by individuals.
} 
$t-1, V_{t-1}(i)$, reads

$$
V_{t-1}(i)=\left\{\begin{array}{c}
\ln \left(1-z^{R}\right)+\ln \left(\frac{\left(1-\tau_{t}\right) I_{t}^{R}(a(i))}{P_{t}}\right) \quad \text { if } i \in \mathcal{R}_{t} \\
\ln \left(1-z^{S}\right)+\ln \left(\frac{\left(1-\tau_{t}\right) I_{t}^{S}}{P_{t}}\right) \text { if } i \in \mathcal{S}_{t} \\
\ln \left(\frac{1-\tau_{t}}{P_{t}}\right) \quad \text { otherwise }
\end{array}\right.
$$

$t \geq 1$. Since individuals differ only in the ability to perform R\&D tasks after acquiring S\&E skills, in equilibrium, each production worker must be indifferent whether to acquire production skills or to remain unskilled. Thus, $\left(1-z^{S}\right) I_{t}^{S}=1$, according to (21). Moreover, (21) implies that individuals choose to become scientist or engineer if $\left(1-z^{R}\right) I_{t}^{R}(a(i)) \geq 1$. Since $I_{t}^{R}(a(i))$ is increasing in $a(i)$ (Lemma 1$)$, there exists a unique threshold ability level at each date $t$, denoted $\tilde{a}_{t}$, which is given by $\left(1-z^{R}\right) I_{t}^{R}\left(\tilde{a}_{t}\right)=1 .{ }^{15}$ Consequently, for any $t \geq 1$, the set of individuals who acquire S\&E skills is given by $\mathcal{R}_{t}=\left\{i \mid a(i) \geq \tilde{a}_{t}\right\}$. Recalling that ability $a$ is uniformly distributed on the unit interval, this implies $s_{t}^{R}=\left(\int_{\mathcal{R}_{t}} d i\right) / L=\int_{\tilde{a}_{t}}^{1} d a=$ $1-\tilde{a}_{t}, t \geq 1$. The following proposition summarizes these results and states, in addition, how educational shares $s_{t}^{R}, s_{t}^{S}$ and $s_{t}^{U}$, and equilibrium income levels of scientists and engineers, $I_{t}^{R}(a(i))$, depend on public policy, $\mu_{t}, G_{t-1}^{R}$ and $G_{t-1}^{S}$.

Proposition 2. (Educational choice and equilibrium income). For any $t \geq 1$,

(a) $I_{t}^{S}=\left(1-z^{S}\right)^{-1}>1$;

(b) there exists a unique threshold ability level

$$
\tilde{a}_{t}=\left[\frac{\left(1-\mu_{t}\right) \Theta}{2\left(1-z^{R}\right) \gamma(\sigma-1)+\left(1-\mu_{t}\right) \Theta}\right]^{\frac{1}{2}} \equiv a^{*}\left(\mu_{t}\right),
$$

$\Theta \equiv 1+\left(1-\gamma-z^{S} \alpha\right)(\sigma-1)>0,{ }^{16}$ such that all members of generation $t-1$ with $a(i) \geq \tilde{a}_{t}$ become RED workers;

(c) $\tilde{a}_{t}=a^{*}\left(\mu_{t}\right)$ is decreasing in $\mu_{t}$, and thus, $s_{t}^{R}=1-\tilde{a}_{t}$ is increasing in $\mu_{t}$;

\footnotetext{
${ }^{15}$ Educational choices do neither depend on the income tax rate, $\tau_{t}$, nor on the price index, $P_{t}$. Thus, the analysis abstracts from distortions of educational decisions through income taxation which would arise from, say, a progressive tax system.

${ }^{16} \Theta>0$ is implied by $\alpha<1, z^{S}<1$ and $\gamma(\sigma-1)<1$.
} 
moreover, both $\tilde{a}_{t}$ and $s_{t}^{R}$ are independent of $G_{t-1}^{k}, k=R, S$;

(d) both $s_{t}^{S}$ and $s_{t}^{U}$ are decreasing in $\mu_{t}$ and independent of $G_{t-1}^{k}, k=R, S$;

(e) finally, we have

$$
I_{t}^{R}(a(i))=\frac{a(i)}{\left(1-z^{R}\right) \tilde{a}_{t}} .
$$

Thus, for all $a(i) \in\left(\tilde{a}_{t}, 1\right], I_{t}^{R}(a(i))$ is increasing in $\mu_{t}$ and independent of $G_{t-1}^{k}$, $k=R, S$.

Comparative-static results in Proposition 2 can be understood as follows. Since changes in public education spending, $G_{t-1}^{R}$ or $G_{t-1}^{S}$, have no impact on income levels for given educational choices of generation $t-1$, according to Lemma 1 , they do not affect educational choices. In contrast, an increase in the $\mathrm{R} \& \mathrm{D}$ subsidy rate, $\mu_{t}$, by raising demand for $\mathrm{R} \& \mathrm{D}$ labor, has a positive impact on the fraction of scientists and engineers in the population, $s_{t}^{R}$, and thus, a negative impact on both $s_{t}^{S}$ and $s_{t}^{U}$. Moreover, note that the additional supply of scientists or engineers induced by an increase in $\mu_{t}$ stems from workers with mediocre abilities. Thus, implementing a R\&D subsidy raises labor income for all individuals who would become researchers even if $\mu_{t}=0$. In other words, an increase in $\mu_{t}$ raises the return to ability, i.e., income $I_{t}^{R}(a(i))$ is increasing in $\mu_{t}$ whenever $a(i)>\tilde{a}_{t}$, despite an increase in the supply of workers who acquire S\&E skills, $s_{t}^{R} L .{ }^{17} \quad$ (Recall that $s^{R} L$ is the total number of R\&D workers, which has to be distinguished from the effective aggregate supply of S\&E skills, $L^{R}=L \int_{a^{*}}^{1} e^{R}(a) d a$.)

To illustrate the latter point in more detail, consider the impact of an increase in $\mu_{t}$ on two inequality measures: first, on earnings inequality within the group of R\&D workers, and second, on inequality between R\&D labor and production workers. As income of R\&D workers is proportional to ability and ability is uniformly distributed, it is appropriate to define a measure of within-group inequality in period $t$, denoted $\sigma_{t}^{R}$, as ratio of the top to bottom earners within this

\footnotetext{
${ }^{17}$ This effect is similar to one derived in Galor and Moav (2000) in a different context in which an increase in technological progress raises the return to innate (and heterogeneous) cognitive ability. In contrast to their analysis, however, in the present context high-ability individuals gain from a policy measure (!), i.e., we have a government-funded increase in earnings inequality.
} 
group, ${ }^{18}$ i.e., $\sigma_{t}^{R} \equiv I_{t}^{R}(1) / I_{t}^{R}\left(\tilde{a}_{t}\right)$. Thus, $\sigma_{t}^{R}=1 / \tilde{a}_{t}$, according to (23). Moreover, between-group inequality, denoted $\sigma_{t}^{R / P}$, is defined as ratio of average income levels between $\mathrm{R} \& \mathrm{D}$ workers, $\bar{I}_{t}^{R} \equiv\left(1 / s_{t}^{R}\right) \int_{\tilde{a}_{t}}^{1} I_{t}^{R}(a) d a$, and production workers, $\bar{I}_{t}^{P} \equiv\left(s_{t}^{S} I_{t}^{S}+s_{t}^{U}\right) /\left(s_{t}^{S}+s_{t}^{U}\right)$, i.e., $\sigma_{t}^{R / P} \equiv \bar{I}_{t}^{R} / \bar{I}_{t}^{P}$. The following result arises.

Proposition 3. (Long-run distributional effects). Both $\sigma_{t}^{R}$ and $\sigma_{t}^{R / P}$ are increasing in $\mu_{t}$, and independent of $G_{t-1}^{k}, k=R, S$.

Thus, even if R\&D subsidies are fully taken into account by individuals in their educational choice, $\mathrm{R} \& \mathrm{D}$ subsidies are positively related to income inequality according to both measures, within-group and between-group inequality. Note that this result does not hinge on a weak short-run supply elasticity of S\&E skills (compare with Proposition 1). Rather it is an implication of the heterogeneity in ability. This is a novel aspect in the literature on R\&D subsidies. In contrast, public provision of education of either kind does not affect earnings inequality, according to Proposition 3. Hence, whether public policy addresses demand or supply of S\&E skills has very different distributional effects. Whereas the analysis suggests that public provision of education may be neutral to inequality, R\&D subsidies to firms are not. As will become apparent, public education expenditure on scientists and engineers also fosters growth unambiguously, i.e., there is no trade-off between equity and efficiency with respect to this policy measure.

The remainder of this section provides comparative-static results regarding the relationship of policy variables to the equilibrium number of firms, $n_{t}$, efficiency units of S\&E skills supplied in total and employed per firm, $L_{t}^{R}$ and $l_{t}^{R}$, respectively, and the wage rate (per efficiency unit) of skilled production labor, $w_{t}^{S}$, for $t \geq 1$. Note that a change in $n_{t}$ affects both product variety in the economy and, if $\varepsilon<1$, also intertemporal R\&D externalities, $\bar{S}_{t-1}$ (see the discussion in section 2.2). Moreover, recall that $l_{t}^{R}=L_{t}^{R} / n_{t}$ is positively related to productivity $A_{t}$, according to (4), and thus, like $w_{t}^{S}$, adversely affects prices, $p_{t}$, according to (14) and (15). The following

\footnotetext{
${ }^{18}$ A similar measure has been applied by Galor and Moav (2000), who also assume a uniform ability distribution. Ability has a different interpretation in their model, however.
} 
results will also play an important role for understanding the socially optimal policy design analyzed in the next section.

Lemma 2. For any $t \geq 1$, the following holds in equilibrium.

$$
\begin{aligned}
n_{t} & =\frac{L a^{*}\left(\mu_{t}\right)[1-\gamma(\sigma-1)]}{f \Theta} \equiv n^{*}\left(\mu_{t}\right), \\
L_{t}^{R} & =\frac{\xi^{R} L^{1-\beta^{R}}\left[1-a^{*}\left(\mu_{t}\right)^{2}\right]}{2}\left(\frac{G_{t-1}^{R}}{1-a^{*}\left(\mu_{t}\right)}\right)^{\beta^{R}} \equiv L^{R *}\left(\mu_{t}, G_{t-1}^{R}\right), \\
l_{t}^{R} & =\frac{f \Theta \xi^{R}\left(G_{t-1}^{R} / L\right)^{\beta^{R}}\left(1+1 / a^{*}\left(\mu_{t}\right)\right)\left(1-a^{*}\left(\mu_{t}\right)\right)^{1-\beta^{R}}}{2[1-\gamma(\sigma-1)]} \equiv l^{R *}\left(\mu_{t}, G_{t-1}^{R}\right), \\
w_{t}^{S} & =\frac{\left[\alpha(\sigma-1) a^{*}\left(\mu_{t}\right)\right]^{\beta^{S}}}{\xi^{S}\left(G_{t-1}^{S} / L\right)^{\beta^{S}}\left(1-z^{S}\right)^{1-\beta^{S}} \Theta^{\beta^{S}}} \equiv w^{S *}\left(\mu_{t}, G_{t-1}^{S}\right) .
\end{aligned}
$$

Thus, an increase in $\mu_{t}$ reduces both $n_{t}$ and $w_{t}^{S}$, and raises $l_{t}^{R}$; the impact of an increase in $\mu_{t}$ on $L_{t}^{R}$ is generally ambiguous, but negative if $\beta^{R}=1$. Moreover, an increase in $G_{t-1}^{R}$ raises both $L_{t}^{R}$ and $l_{t}^{R}$, but has no impact on $n_{t}$ or $w_{t}^{S}$. Finally, an increase in $G_{t-1}^{S}$ lowers $w_{t}^{S}$, but has no impact on $n_{t}, L_{t}^{R}$ or $l_{t}^{R}$.

For the intuition of the impact of a change in $\mu_{t}$ on the variables in (24)-(27), first, recall from Proposition 1 that for given educational choices, R\&D costs of firms and thus the number of firms are unaffected by R\&D subsidies. Also recall from part (iii) of Proposition 2 that an increase in the $\mathrm{R} \& \mathrm{D}$ subsidy rate, $\mu_{t}$, raises the incentive for individuals with mediocre abilities to acquire S\&E skills, i.e., $\tilde{a}_{t}$ declines. In view of the previous remark that $n_{t}$ is unaffected by a change in $\mu_{t}$ for a given fraction $s_{t}^{R}$ of scientists and engineers in the labor force, this shift in the employment structure away from production activities lowers profits of firms due to a reduction in output, all other things equal. Thus, an increase in $\mu_{t}$ adversely affects the equilibrium number of firms, $n^{*}$. Moreover, and somewhat surprisingly at the first glance, total supply of effective R\&D labor, $L^{R *}$, may decrease with $\mu_{t}$ (e.g., if $\beta^{R}=1$ ), despite the fact that a larger fraction $s_{t}^{R}$ of individuals chooses education in a S\&E field. This is because public education is a rival good, i.e., given 
total education spending, effective labor per head is decreasing if more individuals acquire education. Thus, an increase in $s_{t}^{R}$ triggered by an increase in $\mu_{t}$ exerts a negative externality on effective R\&D labor per head, according to (7) and (8). This demonstrates that $R \& D$ subsidies may be a rather ineffective way to stimulate R\&D activity. The analysis also suggests that the primary policy goal should not necessarily be to raise the fraction of scientists and engineers in the population, ${ }^{19}$ but to promote the skill development of the best talents, i.e., to emphasize excellence in the education system.

Due to the decline in the number of firms, efficiency units of S\&E skills per firm, $l^{R *}$, nevertheless increase unambiguously with $\mu_{t}$. Moreover, due to the rivalry of public education expenditure, since less individuals choose to acquire production skills when $\mu_{t}$ increases, for any level $G_{t-1}^{S}$, per capita spending for production skills, $g_{t-1}^{S}$, rises. Thus, effective supply of production skills per worker increases. Consequently, the wage rate per efficiency unit of production skills (relative to the wage rate of the unskilled), $w_{t}^{S}$, declines when $\mu_{t}$ increases.

To understand the effects of changes in educational spending, recall from parts (iii) and (iv) of Proposition 2 that an increase in public education expenditure of either kind, $G_{t-1}^{R}$ or $G_{t-1}^{S}$, leaves population shares, $s_{t}^{R}, s_{t}^{S}$ and $s_{t}^{U}$, unchanged. Thus, an increase in $G_{t-1}^{R}$ does not affect $n^{*}$ or $w^{S *}$, but raises effective R\&D labor in total and per firm, $L^{R *}$ and $l^{R *}$, respectively. In contrast, since an increase in $G_{t-1}^{S}$ raises effective labor supply of skilled production workers, it lowers $w^{S *}$, without affecting $n^{*}, L^{R *}$ or $l^{R *}$.

Note from Proposition 2 and Lemma 2 that the economy is in its steady state from period 1 onwards if public policy does not change over time, i.e., if

$$
\mu_{t}=\bar{\mu}, G_{t}^{R}=\bar{G}^{R}, \text { and } G_{t}^{S}=\bar{G}^{S} \text { for all } t \geq 1
$$

\footnotetext{
${ }^{19}$ To avoid misunderstandings, this presumes that there are no obstacles to attract the best talents to S\&E fields. For instance, a much discussed policy debate are gender-specific attitudes to S\&E fields in particular and problems to attract ethnic minorities to tertiary education in general (see e.g. European Commission, 2003). The analysis has nothing to say about such important issues, which should be tackled by future research.
} 
The next result analyzes the effects of public policy for the rate of productivity growth, $\vartheta_{t+1} \equiv A_{t+1} / A_{t}-1$.

Proposition 4. (Productivity growth). Suppose $\mu_{t}=\bar{\mu}$ holds for all $t \geq 1$. Then,

$$
\vartheta_{1}=\left(n_{0}\right)^{1-\varepsilon} l^{R *}\left(\bar{\mu}, G_{0}^{R}\right)-1 \text {, and for } t \geq 1, \vartheta_{t+1}=n^{*}(\bar{\mu})^{1-\varepsilon} l^{R *}\left(\bar{\mu}, G_{t}^{R}\right)^{\gamma}-1 \text {. }
$$

Thus, for all $t \geq 0$, an increase in $\bar{\mu}$ unambiguously raises $\vartheta_{t+1}$ if $\varepsilon=1$, whereas, for $t \geq 1$, the impact of an increase in $\bar{\mu}$ on $\vartheta_{t+1}$ is generally ambiguous if $\varepsilon<1$. Moreover, for all $t \geq 1$, an increase in $G_{t}^{R}$ positively affects $\vartheta_{t+1}$, whereas $\vartheta_{t+1}$ is independent of $G_{t}^{S}$.

Let us start with the relationship between R\&D subsidies and productivity growth. Recall from the discussion in section 2.2 that, if $\varepsilon<1$, the number of innovating firms, $n$, positively affects knowledge spillovers in symmetric equilibrium (which is prevalent in the model), all other things equal. Thus, under (28), if $\varepsilon<1$, an increase in $\bar{\mu}$ (which is foreseen by individuals when making educational choices) has two opposing effects on productivity growth, $\vartheta_{t+1}, t \geq 1$. First, it raises effective R\&D labor per firm, $l^{R *}$, according to Lemma 2. Second, however, it reduces the number of innovating firms, $n^{*}$, which has a negative effect on knowledge spillovers. If $\varepsilon=1$, all innovations are equivalent in the sense that the number of innovating firms does not matter for knowledge spillovers, i.e., the second effect vanishes. ${ }^{20}$ Thus, only in this case, productivity growth is unambiguously fostered by R\&D subsidies. $^{21}$

\footnotetext{
${ }^{20}$ According to $(29)$, the growth rate in period $1, \vartheta_{1}$, is unambiguously increasing in $\bar{\mu}$ also if $\varepsilon<1$.

${ }^{21}$ Although $\varepsilon=1$ seems to be a knife-edge case, one should note that it has a desirable property of removing "scale effects" regarding growth, holding per capita spending on S\&E skills, $G^{R} / L$, constant. That is, according to (24) and (26), productivity growth does not depend on population size $L$ if $\varepsilon=1$. (However, it is easy to see that even in the case $\varepsilon=1$, there are scale effects regarding the level of productivity $A_{t}$, and thus, regarding the level of output, respectively. See Jones (1999) for a discussion of this property of so-called non-scale models of endogenous growth.)
} 
Next, let us discuss the implications of public education policy for productivity growth. Recall from Lemma 2 that public education spending of either kind is unrelated to the number of firms, and thus does not affect intertemporal R\&D externalities. Also note that public spending on S\&E skills, unlike educational spending on production skills, affects innovative activity per firm. This explains why educational spending on scientists and engineers but not on other skilled workers is positively related to productivity growth. ${ }^{22}$ Public education targeted to production skills affects welfare, however, as will become apparent in the following.

\section{Normative Analysis}

This section examines implications of the positive analysis on both the desirability of R\&D subsidies and the optimal structure of public education expenditure from a normative point of view.

First, consider the public finance side of policy measures, which relates policy variables to the required income tax rates under a balanced government budget.

Lemma 3. With a balanced public budget, income tax rates are given by

$$
\tau_{0}=\frac{\frac{\left(G_{0}^{R}+G_{0}^{S}\right) \Xi}{L_{0}^{U}}+\frac{\gamma(\sigma-1) \mu_{0}}{1-\mu_{0}}}{\sigma+\frac{\gamma(\sigma-1) \mu_{0}}{1-\mu_{0}}} \equiv \tilde{\tau}_{0}\left(G_{0}^{R}, G_{0}^{S}, \mu_{0}\right)
$$

and, for all $t \geq 1$,

$$
\tau_{t}=\frac{\frac{\left(G_{t}^{R}+G_{t}^{S}\right) \Theta}{L a^{*}\left(\mu_{t}\right)}+\frac{\gamma(\sigma-1) \mu_{t}}{1-\mu_{t}}}{\sigma+\frac{\gamma(\sigma-1) \mu_{t}}{1-\mu_{t}}} \equiv \tilde{\tau}\left(G_{t}^{R}, G_{t}^{S}, \mu_{t}\right) .
$$

In contrast, if $\varepsilon<1$, productivity growth is increasing in $L$ (again, holding $G^{R} / L$ constant). Empirical evidence on the presence of scale effects regarding the long-run growth rate is, however, weak and inconclusive (for a comprehensive survey, see e.g. Dinopoulos and Thompson, 1999). That is, scale effects, although seemingly playing a major role in historical growth paths (Kremer, 1993), have been severely questioned for the post-war period (e.g., Jones, 1995, 2003). This does not necessarily mean, however, that $\varepsilon=1$ is the empirically relevant case, although it may mean that the model is not fully appropriate to deal with the scale effect problem which is prevalent in many models of endogenous technical change.

${ }^{22}$ As argued in an earlier note, this property is well-supported by empirical evidence (e.g., Murphy, Shleifer and Vishny, 1991). 
Thus, for all $t \geq 0, \tau_{t}$ is increasing in $\mu_{t}$ and $G_{t}^{k}, k=R, S .{ }^{23}$

Welfare of the initially old generation may be represented by some function $f\left(\tau_{0}, \mu_{0}\right)$, which negatively depends on the income tax rate, $\tau_{0}=\tilde{\tau}_{0}\left(G_{0}^{R}, G_{0}^{S}, \mu_{0}\right)$, and, possibly, positively depends on the initial R\&D subsidy, $\mu_{0}$ (because it raises income levels of scientists and engineers, according to Proposition 1). Moreover, to ensure an interior solution with respect to the socially optimal choice of $G_{0}^{k}, k=R, S$, suppose $\partial^{2} f / \partial\left(\tau_{0}\right)^{2} \leq 0$. The function $f$ depends, in addition to a specification of social welfare for this generation, on the allocation of skills across adult individuals in the initial period, which has not been specified yet. An explicit derivation of $f$ from such specifications would not yield further insights for the optimal policy mix, however, and is therefore left out.

First, recall that $\mu_{0}$ plays no role for subsequent generations (i.e., does not trigger intertemporal knowledge spillovers), and merely affects the income distribution of the initially old generation, according to Proposition 1. Thus, if the social planner has no preference for windfall gains of $R \& D$ workers (in the initial period), we have $\mu_{0}=0$ in social optimum. ${ }^{24}$

For the sake of concreteness, suppose that the social planner maximizes the discounted sum of welfare of each generation. Moreover, let us employ an utilitarian welfare function for each generation. The social welfare function is then given by

$$
W=f\left(\tau_{0}, \mu_{0}\right)+\sum_{t=1}^{\infty} \rho^{t} \int_{i \in[0, L]} V_{t-1}(i) d i
$$

where $\rho \in(0,1)$ is the time preference rate of the social planer. ${ }^{25}$ (Recall that $V_{t-1}(i)$ is indirect utility of member $i$ of generation $t-1$.)

Due to the lack of transitional dynamics in the model, the social planning prob-

\footnotetext{
${ }^{23}$ Recall that $\Xi$ and $\Theta$ are unessential, positive constants.

${ }^{24}$ Formally, this is true if $\partial f\left(\tau_{0}, \mu_{0}\right) /\left.\partial \tau_{0}\right|_{\tau_{0}=\tau_{0}} \cdot \partial \tilde{\tau}_{0} / \partial \mu_{0}+\partial f\left(\tilde{\tau}_{0}, \mu_{0}\right) / \partial \mu_{0} \leq 0$ for all $\left(G_{0}^{R}, G_{0}^{S}, \mu_{0}\right)$ such that $\tilde{\tau}_{0}\left(G_{0}^{R}, G_{0}^{S}, \mu_{0}\right)<1$. (Note that $\partial \tilde{\tau}_{0} / \partial \mu_{0}>0$, according to Lemma 3, and recall assumptions $\partial f / \partial \tau_{0}<0$ and $\partial f / \partial \mu_{0} \geq 0$.)

${ }^{25}$ Discounting of future generations may be normatively justified by the presence of positive productivity growth.
} 
lem entails that (28) holds, i.e., policy variables are time-invariant for $t \geq 1 .^{26}$ The socially optimal R\&D policy, given constraint $\bar{\mu} \geq 0$ (a non-negative R\&D subsidy rate is imposed in order to allow for a well-defined corner solution of the social planning problem), can be characterized as follows.

Proposition 5. (Optimal R\&D subsidy). For all $t \geq 1$, the socially optimal $R \mathscr{G} D$ subsidy rate may be given by $\mu_{t}=\bar{\mu}=0$. Provision of REBD subsidies is "more likely" to be detrimental to social welfare, the lower $\varepsilon$ or $\beta^{S}$, and the higher $\beta^{R}$, but $\bar{\mu}=0$ may also be optimal if $\varepsilon=1$.

According to Proposition 5, although a positive intertemporal spillover effect is the only externality from $R \& D$, it may well be the case that providing $R \& D$ subsidies is harmful. To gain intuition for this result, recall that, for any $t \geq 1$, an increase in $\mu_{t}=\bar{\mu}$ lowers the number of firms and products, $n_{t}=n^{*}(\bar{\mu})$, according to Lemma 2. This has two adverse effects on social welfare. First, except for the initially old generation, utility of all individuals declines due to the love-of-variety property of preferences. Second, if $\varepsilon<1$, steady state productivity growth (driven by knowledge spillovers) may slow down when $\bar{\mu}$ increases, according to Proposition 4 , even though S\&E skills employed per firm rise unambiguously. This effect is more likely to be negative, the lower $\varepsilon$ is. However, even if an increase in $\bar{\mu}$ unambiguously raises productivity growth (i.e., if $\varepsilon=1$ ), it is optimal not to provide a demand-stimulus to R\&D under plausible parameter configurations (for an example, see the proof of Proposition 5 in Appendix).

Also $\beta^{R}$ and $\beta^{S}$, which may be interpreted as the effectiveness of public education expenditure for the development of S\&E skills and production skills, according to (8) and (9), respectively, systematically affect the socially optimal R\&D subsidy. First, recall that an anticipated increase in $\mu_{t}$ raises the employment share of scientists and engineers, $s_{t}^{R}$, and lowers the employment share of skilled production workers, $s_{t}^{S}$, according to parts (iii) and (iv) of Proposition 2, respectively. Thus, since education is a rival good, for any level $G_{t-1}^{S}$, the positive effect of $\mu_{t}$ on utility

\footnotetext{
${ }^{26}$ Thus, for $t \geq 1, \tau_{t}$ is time-invariant, according to (31).
} 
through a reduction in $s_{t}^{S}$ and thus in $w^{S *}$ (which lowers marginal production costs) is strengthened by an increase in $\beta^{S}$. In contrast, for any level $G_{t-1}^{R}$, the positive effect of $\mu_{t}$ on utility through an increase in $s_{t}^{R}$ and thus in $l^{R *}$ is weakened by an increase in $\beta^{R} .{ }^{27}$

Proposition 6. (Optimal structure of public education). The socially optimal structure of public education expenditure can be characterized as follows.

(a) $G_{0}^{R} / G_{0}^{S}=\gamma \beta^{R} /\left(\alpha \beta^{S}\right)$ and, for all $t \geq 1$,

$$
\frac{G_{t}^{R}}{G_{t}^{S}}=\frac{\bar{G}^{R}}{\bar{G}^{S}}=\frac{(2-\rho) \gamma \beta^{R}}{(1-\rho) \alpha \beta^{S}}
$$

(b) For all $t \geq 0$, for a given policy to subsidize $R \mathscr{E} D, G_{t}^{R}\left(G_{t}^{S}\right)$ is increasing (decreasing) in $\beta^{R}$, and decreasing (increasing) in $\beta^{S}$; moreover, both $G_{t}^{R}$ and $G_{t}^{S}$ are independent of $\varepsilon, \xi^{R}$ and $\xi^{S}$.

According to Proposition 6 (a), for all $t \geq 0$, the socially optimal structure of education spending, $G_{t}^{R} / G_{t}^{S}$, positively depends on the relative effectiveness of the education technology, $\beta^{R} / \beta^{S}$, and the effectiveness of $\mathrm{R} \& \mathrm{D}$ relative to the output elasticity of production skills, $\gamma / \alpha$. Moreover, the educational production technology and technologies of firms to produce innovations and output, respectively, interact: the higher the relative effectiveness of $\mathrm{R} \& \mathrm{D}, \gamma / \alpha$, the higher the impact of an increase in the relative effectiveness of the education technology, $\beta^{R} / \beta^{S}$, on the optimal relative education spending on S\&E skills, $G_{t}^{R} / G_{t}^{S}$, and vice versa. ${ }^{28}$

According to Proposition 6 (b), expenditure levels for each type of skills positively depend on the effectiveness of developing this type of skills in the education

\footnotetext{
${ }^{27}$ If one would allow for different weights attached to low-ability and high-ability individuals in the social welfare function, one can show that the introduction of a $R \& D$ subsidy is more likely to harm social welfare, the lower social preferences for high-ability types. This is because R\&D subsidies affect long-run income inequality by favoring high-ability individuals, according to Proposition 3. Thus, in this sense, also distributional concerns greatly matter for the socially optimal policy design to promote R\&D.

${ }^{28}$ According to (33), for $t \geq 1, G_{t}^{R} / G_{t}^{S}=\bar{G}^{R} / \bar{G}^{S}$ is also increasing in the time preference parameter $\rho$. If the social planner discounts the future to a lesser degree (i.e., if $\rho$ increases), then the knowledge spillover becomes more important for intertemporal welfare. As a result, the optimal education structure shifts towards S\&E skills.
} 
technology and are adversely related to the effectiveness of developing the other skill type. Moreover, since public education policy does not affect the equilibrium number of firms, a change in $\varepsilon$, which is critical for knowledge spillovers, has no impact on the optimal public education policy. Finally, educational productivity parameters $\xi^{R}$ and $\xi^{S}$ in (8) and (9), respectively, neither play a role for the structure nor for the level of the socially optimal education expenditure. Increases in $\xi^{R}$ or $\xi^{S}$ leave the elasticity of effective labor with respect to per capita spending levels on education, $g^{R}$ or $g^{S}$, respectively, unchanged, and thus do not alter the optimal education policy.

\section{Concluding Remarks}

The question how to promote $R \& D$ activity in order to enhance productivity growth is at the center of public policy debates. Almost a third of R\&D expenditure in the OECD is financed by the government sector, e.g., through grants, project funding or tax incentives (OECD, 1999). At present, the EU is planning an initiative to further raise financial incentives to $R \& D$ performing firms over the next years significantly (COM, 2003). Indeed, empirical studies have frequently estimated positive and quite sizable effects of government support to business R\&D. For instance, in a survey article on the effectiveness of fiscal incentives for R\&D, Hall and van Reenen (2000, p.462) argue that "work using US firm-level data all reaches the same conclusion: the tax price elasticity of total R\&D spending during the 1980s is on the order of unity". ${ }^{29}$ However, as pointed out by Goolsbee (1998, p.298), "[w] hen the government increases R\&D spending through subsidies or direct provision, a significant fraction of the increased spending goes directly into higher wages, an increase in the price rather than the quantity of inventive activity". Remarkably, this empirical

\footnotetext{
${ }^{29}$ Guellec and Pottelsberghe (2003) show that the impact of an increase in public expenditure on business R\&D expenditure (using data from 17 OECD countries for the 1983-96 period) is positive also in the aggregate. Moreover, their evidence suggests that an increased incentive in direct government funding reduces the effect of tax incentives and vice versa, showing that different demand-side policies to $R \& D$ are substitutes to each other.
} 
finding does not only hold in the short-run but also in the longer-run. ${ }^{30}$ Indeed, R\&D capital expenditure typically accounts for only 10-13 percent of business $R \& D$ (e.g., Hall and van Reenen, 2000), so it is fair to say that demand-side R\&D policy has mainly to be evaluated on the basis whether or not it stimulates employment of S\&E skills.

By assuming that a given (high-skilled) labor force can be allocated freely between production-related activities and R\&D tasks, standard R\&D-based growth models have given a definite answer to the question whether $\mathrm{R} \& \mathrm{D}$ subsidies are desirable: Whenever positive externalities from $R \& D$ exceed the negative ones, $R \& D$ performing firms should be subsidized. However, this literature has not taken into account the specificity of S\&E skills and the heterogeneity of individual ability, where ability determines educational choice. By allowing for these elements, the analysis predicts that, even in the long-run, $\mathrm{R} \& \mathrm{D}$ subsidies raise labor income inequality across groups of R\&D and production workers and within the group of scientists and engineers. This is because R\&D subsidies raise the return to ability of scientists and engineers except for the marginal entrant in a S\&E field. Moreover, due to the rivalry of education expenditure, effective aggregate supply of S\&E skills may not increase in response to higher R\&D subsidies. If innovations are non-equivalent, this implies that productivity growth may slow down. In addition, R\&D subsidies may be detrimental to welfare by fostering concentration, even though knowledge spillovers are the only (and positive) R\&D externality in the model. ${ }^{31}$

As an alternative measure to promote $\mathrm{R} \& \mathrm{D}$, an increase in public expenditure

\footnotetext{
${ }^{30}$ These distributional effects may be quite substantial even at the macro level. In 1999, the U.S. workforce included about 3.5 million individuals employed in S\&E occupations, where almost 2.26 million were employed in private, for-profit industries (National Science Board, 2002, Appendix table 3-12). An additional 3.35 million people whose highest degree is in a S\&E field but who are classified as holding non-S\&E occupations indicate that their job is closely or somewhat related to the field of their highest S\&E degree (National Science Board, 2002, table 3-2). In total, around 11 million people in the U.S. graduated in a S\&E field.

${ }^{31}$ One may argue that this potentially negative relationship of $R \& D$ subsidies to welfare is a consequence of the modeling strategy to take labor as only input of the R\&D technology. However, if anything, this argument calls for a special subsidy on R\&D equipment, which accounts for a comparatively low fraction of total R\&D costs, rather than for a general subsidy on R\&D spending (Romer, 2000).
} 
targeted to the education of scientists and engineers neither affects the income distribution nor concentration in the economy, but unambiguously raises productivity growth. That is, because $\mathrm{R} \& \mathrm{D}$ activity primarily requires human resources with specialized skills, government policy should try to support the best talents by providing a high-standard S\&E education. Interestingly, the widely-recognized "Sapir-Report" of a group of top economists on growth-promoting policies for Europe (on the initiative of the President of the European Commission) recommends a "substantial increase in government and EU spending for [...] postgraduate education, but at the same time putting the main emphasis on excellence when allocating the new additional funds" (Sapir et al., 2004, p.134; italics original). The analysis has given a theoretical foundation to this policy prescription; first, by pointing out that the often heard distributional concern to an education system which aims at promoting excellence in ability of students and researchers is mistaken, and second, by showing that such a policy will unambiguously boost efficiency and growth. Moreover, the analysis has accounted for the welfare-enhancing effects of public education targeted to non-S\&E fields as well. The optimal structure of public education spending towards different skills depends on the relative effectiveness of the education sector across fields and its interaction with the technological characteristics of firms' R\&D and production activity.

The analysis also suggests to reconsider the policy-mix of public expenditure to promote growth. Even if R\&D subsidies were socially desirable due to a potential rise in S\&E skills, awareness and credibility of future public support for business R\&D has to be enhanced in order to attract students to S\&E fields. ${ }^{32}$ Otherwise, the dismal short-run effect identified in the analysis could be prevalent for quite a long period. Thus, by and large, supporting supply of S\&E skills directly over the education system rather than indirectly through demand-side policies seems to be preferable.

\footnotetext{
${ }^{32}$ Evidence by Guellec and Pottelsberghe (2003) suggests that both direct public funding of R\&D and fiscal incentives are more effective in raising private $R \& D$ expenditure when their provision is more stable over time.
} 
However, by focussing on spending levels for the development of specific skills, the analysis has just scratched the surface on how to improve the education system in order to enhance growth and welfare. For instance, the analysis has neglected the apparent cyclicity and uncertainty of private-sector demand for scientists and engineers (De Hek, 1999; De Hek and Santanu, 2001), which may give a disincentive to enter S\&E fields. Moreover, the analysis has not addressed the concerns related to gender-specific attitudes to S\&E education and failures in primary and secondary level school systems which lead to an insufficient attraction of the best talents to higher-level education in general and S\&E fields in particular (e.g., European Commission, 2003). The consequences of these issues for public policy measures towards R\&D-based growth are left for future research.

\section{Appendix}

Proof of Lemma 1. First, using both (5) and the fact that $\left(p_{t}-c_{t}\right) x_{t}^{D}=$ $\left[\bar{S}_{t-1} h\left(l_{t}^{R}\right) P_{t} /\left(w_{t}^{S}\right)^{\alpha}\right]^{\sigma-1} \Gamma E_{t}$ in symmetric equilibrium (see (17)), (18) implies

$$
\left(p_{t}-c_{t}\right) x_{t}^{D}(\sigma-1) \gamma=\left(1-\mu_{t}\right) w_{t}^{R} l_{t}^{R}
$$

for any $t \geq 0$ in symmetric equilibrium. Combining (A.1) with the free entry condition (E3), we obtain

$$
w_{t}^{R} l_{t}^{R}=\frac{f \gamma(\sigma-1)}{\left(1-\mu_{t}\right)[1-\gamma(\sigma-1)]}
$$

Note that $p_{t}-c_{t}=c_{t} /(\sigma-1)$ in symmetric equilibrium, according to (14). Thus, substituting condition (E1) and (A.2) into (A.1) leads to

$$
c_{t} A_{t}\left(l_{t}^{S}\right)^{\alpha}\left(l_{t}^{U}\right)^{1-\alpha}=\frac{f(\sigma-1)}{1-\gamma(\sigma-1)} .
$$


Moreover, according to (3), the wage rate per efficiency unit of skilled labor in production (relative to unskilled labor) fulfills

$$
w_{t}^{S}=\frac{\alpha}{1-\alpha} \frac{l_{t}^{U}}{l_{t}^{S}}
$$

(recall $w_{t}^{U}=1$ ). Substituting (15) and (A.4) into (A.3) yields

$$
l_{t}^{U}=\frac{(1-\alpha) f(\sigma-1)}{1-\gamma(\sigma-1)}
$$

for any $t \geq 0$. Substituting (A.5) into the labor market clearing condition (E2) for unskilled labor, we find that, for any $t \geq 0$, the number of firms is given by

$$
n_{t}=\frac{L_{t}^{U}[1-\gamma(\sigma-1)]}{f \Xi}
$$

where $\Xi=1+(1-\alpha-\gamma)(\sigma-1)$ has been used. Consequently, combining (A.6) with condition (E2) for skilled labor of type $k=R, S$, respectively, one obtains

$$
l_{t}^{k}=\frac{L_{t}^{k} f \Xi}{L_{t}^{U}[1-\gamma(\sigma-1)]}
$$

For $k=R$, substituting (A.7) into (A.2) implies that, for $t \geq 0$, the wage rate per efficiency unit of R\&D labor is given by

$$
w_{t}^{R}=\frac{L_{t}^{U} \gamma(\sigma-1)}{\left(1-\mu_{t}\right) L_{t}^{R} \Xi}
$$

Similarly, substituting both (A.7) for $k=S$ and (A.5) into (A.4) yields, for $t \geq 0$,

$$
w_{t}^{S}=\frac{L_{t}^{U} \alpha(\sigma-1)}{L_{t}^{S} \Xi} .
$$

Next, note that for all $t \geq 1$, total efficiency units of $R \& D$ labor are given by

$$
L_{t}^{R}=\int_{\mathcal{R}_{t}} e_{t}^{R}(a(i)) d i=\xi^{R}\left(g_{t-1}^{R}\right)^{\beta^{R}} \int_{\mathcal{R}_{t}} a(i) d i
$$


where (8) has been used for the latter equation. Similarly, using (9), one finds

$$
L_{t}^{S}=s_{t}^{S} L \xi^{S}\left(g_{t-1}^{S}\right)^{\beta^{S}}
$$

for the total efficiency units of skilled production labor. Total supply of unskilled labor is given by

$$
L_{t}^{U}=L s_{t}^{U}=L\left(1-s_{t}^{R}-s_{t}^{S}\right)
$$

Using (A.10)-(A.12), (A.8) and (A.9) can be written as

$$
\begin{gathered}
w_{t}^{R}=\frac{L\left(1-s_{t}^{R}-s_{t}^{S}\right) \gamma(\sigma-1)}{\left(1-\mu_{t}\right) \Xi \xi^{R}\left(g_{t-1}^{R}\right)^{\beta^{R}} \int_{\mathcal{R}_{t}} a(i) d i}, \\
w_{t}^{S}=\frac{\left(1-s_{t}^{R}-s_{t}^{S}\right) \alpha(\sigma-1)}{s_{t}^{S} \xi^{S}\left(g_{t-1}^{S}\right)^{\beta^{S}} \Xi} .
\end{gathered}
$$

Finally, substituting (A.13) and (A.14) into (10) confirms (19) and (20), respectively. Comparative-static results immediately follow. This concludes the proof.

Proof of Proposition 1. The results regarding the impact of an increase in $\mu_{0}$ on $n_{0}, w_{0}^{R}$ and $w_{0}^{S}$ follow from (A.6), (A.8) and (A.9), respectively, considering $t=0$. (Recall that $L_{0}^{R}, L_{0}^{S}$ and $L_{0}^{U}$ are exogenous.) Moreover, note that, in equilibrium (which is symmetric), $A_{0}=\bar{S}_{-1} h\left(l_{0}^{R}\right)=\bar{S}_{-1}\left(l_{0}^{R}\right)^{\gamma}$, according to (4) and (5). Using $l_{0}^{R}=L_{0}^{R} / n_{0}$ from (E2), and recalling that $S_{-1}$ is exogenously given, concludes the proof.

Proof of Proposition 2. Part (a) follows from equilibrium condition (1 $\left.z^{S}\right) I_{t}^{S}=1$. To prove part (b), first, combine (20) and $I_{t}^{S}=\left(1-z^{S}\right)^{-1}$, and use $\tilde{a}_{t}=1-s_{t}^{R}$ to obtain

$$
s_{t}^{S}=\frac{\left(1-z^{S}\right) \alpha(\sigma-1) \tilde{a}_{t}}{\Theta}
$$

where $\Theta=1+\left(1-\gamma-z^{S} \alpha\right)(\sigma-1)$ has been used. (Also recall $\Xi=1+(1-\alpha-\gamma)(\sigma-1)$, 
which has been used to derive (A.15).) Combining (A.15) and $\tilde{a}_{t}=1-s_{t}^{R}$ yields

$$
s_{t}^{U}=1-s_{t}^{R}-s_{t}^{S}=\frac{\Xi \tilde{a}_{t}}{\Theta} .
$$

Moreover, recalling that $a(i) \sim$ uniform $\{0,1\}$, we have

$$
\int_{\mathcal{R}_{t}} a(i) d i=L \int_{\tilde{a}_{t}}^{1} a d a=\frac{L\left(1-\left(\tilde{a}_{t}\right)^{2}\right)}{2} .
$$

for all $t \geq 1$. Substituting both (A.16) and (A.17) into (19), we obtain

$$
I_{t}^{R}(a(i))=\frac{a(i) \gamma(\sigma-1)}{\left(1-\mu_{t}\right) \Theta} \frac{2 \tilde{a}_{t}}{1-\left(\tilde{a}_{t}\right)^{2}} .
$$

Thus, combining (A.18) with equilibrium condition $\left(1-z^{R}\right) I_{t}^{R}\left(\tilde{a}_{t}\right)=1$ and rearranging terms confirms part (b). Part (c) follows from (22) and the fact that $s_{t}^{R}=1-\tilde{a}_{t}$. Moreover, according to (A.15) and (A.16), respectively, both $s_{t}^{S}$ and $s_{t}^{U}$ are decreasing in $\mu_{t}$ and independent of $G_{t-1}^{k}$ for $k=R, S, t \geq 1$. This confirms part (d). Finally, substituting (22) into (A.18) confirms (23). Thus, using the fact that $\tilde{a}_{t}$ is decreasing in $\mu_{t}$ proves part (e). This concludes the proof.

Proof of Proposition 3. The result that $\sigma^{R}=1 / \tilde{a}_{t}$ increases in $\mu_{t}$ immediately follows from part (c) of Proposition 2. For the impact of an increase of $\mu_{t}$ on $\sigma_{t}^{R / P}=\bar{I}_{t}^{R} / \bar{I}_{t}^{P}$, first, note that one can write

$$
\bar{I}_{t}^{P}=\frac{\left(s_{t}^{S} / s_{t}^{U}\right) I_{t}^{S}+1}{s_{t}^{S} / s_{t}^{U}+1}
$$

Since $I_{t}^{S}=\left(1-z^{S}\right)^{-1}\left(\right.$ see part (a) of Proposition 2) and $s_{t}^{S} / s_{t}^{U}=\left(1-z^{S}\right) \alpha(\sigma-1) / \Xi$, according to (A.15) and (A.16), $\bar{I}_{t}^{P}$ is independent of policy parameters $\mu_{t}, G_{t-1}^{R}$ and $G_{t-1}^{S}$. Substituting both $(23)$ and $s_{t}^{R}=1-\tilde{a}_{t}$ into the expression for the average income of scientists and engineers, $\bar{I}_{t}^{R}=\left(1 / s_{t}^{R}\right) \int_{\tilde{a}_{t}}^{1} I_{t}^{R}(a) d a$, leads to

$$
\bar{I}_{t}^{R}=\frac{1}{2\left(1-z^{R}\right)}\left(\frac{1}{\tilde{a}_{t}}+1\right)
$$


Hence, $\bar{I}_{t}^{R}$, and thus, $\sigma_{t}^{R / P}=\bar{I}_{t}^{R} / \bar{I}_{t}^{P}$ are increasing in $\mu_{t}$, according to part (iii) of Proposition 2. This concludes the proof.

Proof of Lemma 2. Note that, for any $t \geq 1, L_{t}^{U}=L \Xi \tilde{a}_{t} / \Theta$ in equilibrium, according to (A.12) and (A.16). Substituting this into (A.6) and using $\tilde{a}_{t}=a^{*}\left(\mu_{t}\right)$ from (22) confirms (24). To prove (26), first, recall that $g_{t-1}^{R}=G_{t-1}^{R} /\left(s_{t}^{R} L\right), t \geq 1$, according to (7). Substituting this and (A.17) into (A.10) and recalling both $s_{t}^{R}=$ $1-\tilde{a}_{t}$ and $\tilde{a}_{t}=a^{*}\left(\mu_{t}\right)$ for all $t \geq 1$, confirms (25). Thus, using $l_{t}^{R}=L_{t}^{R} / n_{t}$ from (E2), (26) follows from (24) and (25). To prove (27), substitute $g_{t-1}^{S}=G_{t-1}^{S} /\left(s_{t}^{S} L\right)$ from (7) into (A.14), and use (A.15) and (A.16). Comparative static results are obtained from (24)-(27) together with the facts that $\partial \tilde{a}_{t} / \partial \mu_{t}<0$ and $\partial \tilde{a}_{t} / \partial G_{t-1}^{k}=0, k=R, S$, according to part (iii) of Proposition 2. (For the impact of an increase in $\mu_{t}$ on $L_{t}^{R}$ if $\beta^{R}=1$, note that $L_{t}^{R}=\xi^{R}\left[1+a^{*}\left(\mu_{t}\right)\right] G_{t-1}^{R} / 2$ if $\beta^{R}=1$, according to (25).) This concludes the proof.

Proof of Proposition 4. Using (4) and (6), it is straightforward to show that

$$
A_{1}=\bar{S}_{0}\left(l_{1}^{R}\right)^{\gamma} \text { and, for } t \geq 2, A_{t}=\bar{S}_{0}\left(n_{t-1} \cdot \ldots \cdot n_{1}\right)^{1-\varepsilon}\left(l_{t}^{R} \cdot \ldots \cdot l_{1}^{R}\right)^{\gamma}
$$

where $\bar{S}_{0}=\bar{S}_{-1}\left(n_{0}\right)^{1-\varepsilon}\left(l_{0}^{R}\right)^{\gamma}$, according to (4), (5) and the symmetry of equilibrium. Thus, $\bar{S}_{0}$ is exogenously given (see (A.6) and the proof of Proposition 1). Also recall $A_{0}=\bar{S}_{-1}\left(l_{0}^{R}\right)^{\gamma}$. Thus, $A_{1} / A_{0}=\left(n_{0}\right)^{1-\varepsilon}\left(l_{1}^{R}\right)^{\gamma}$ and, for all $t \geq 1, A_{t+1} / A_{t}=$ $\left(n_{t}\right)^{1-\varepsilon}\left(l_{t+1}^{R}\right)^{\gamma}$. Using (24) and (26) confirms the results.

Proof of Lemma 3. At each date $t \geq 0$, the government budget constraint reads

$$
\tau_{t} Y_{t}=G_{t}^{R}+G_{t}^{S}+\mu_{t} w_{t}^{R} L_{t}^{R}
$$

where $Y_{t} \equiv w_{t}^{R} L_{t}^{R}+w_{t}^{S} L_{t}^{R}+L_{t}^{U}$ is aggregate (nominal) income. Using (A.8) and (A.9), it is easy to show that $Y_{t}$ is given by

$$
Y_{t}=\frac{L_{t}^{U}}{\Xi}\left(\sigma+\frac{\gamma(\sigma-1) \mu_{t}}{1-\mu_{t}}\right)
$$


(Recall $\Xi=1+(1-\alpha-\gamma)(\sigma-1)$.) Substituting (A.8) and (A.22) into (A.21), and rearranging terms, yields

$$
\tau_{t}=\frac{\frac{\left(G_{t}^{R}+G_{t}^{S}\right) \Xi}{L_{t}^{U}}+\frac{\gamma(\sigma-1) \mu_{t}}{1-\mu_{t}}}{\sigma+\frac{\gamma(\sigma-1) \mu_{t}}{1-\mu_{t}}}
$$

Setting $t=0$, (A.23) confirms (30). To confirm (31), substitute $L_{t}^{U}=L s_{t}^{U}$, where $s_{t}^{U}$ is given by (A.16), into (A.23). Comparative static results regarding $G_{t}^{k}, k=R, S$, $t \geq 0$, are obvious. Regarding the impact of an increase in $\mu_{0}$ on $\tau_{0}$, it is easy to show from (30) that $\partial \tau_{0} / \partial \mu_{0}>0$ if and only if $\tau_{0}<1$ (which, of course, is presumed). Moreover, using the fact $\left(a^{*}\right)^{\prime}\left(\mu_{t}\right)<0$ (part (iii) of Proposition 2), it is straightforward to show that, for any $t \geq 1$, (31) implies $\partial \tau_{t} / \partial \mu_{t}>0$ if (but not only if) $\tau_{t}<1$. This concludes the proof.

Proof of Proposition 5. First, social welfare is derived as function of policy variables. Substituting both $I_{t}^{S}=\left(1-z^{S}\right)^{-1}$ and (23) from Proposition 2 into (21) yields

$$
V_{t-1}(i)=\left\{\begin{array}{cc}
\ln \left(1-\tau_{t}\right)-\ln P_{t}+\ln \left(a(i) / \tilde{a}_{t}\right) \text { if } i \in \mathcal{R}_{t} \\
\ln \left(1-\tau_{t}\right)-\ln P_{t} \quad \text { otherwise }
\end{array}\right.
$$

Moreover, making use of the symmetry of equilibrium, (12) implies $P_{t}=\left(n_{t}\right)^{\frac{1}{1-\sigma}} p_{t}$. Thus, using (14) and (15),

$$
-\ln P_{t}=\frac{\ln n_{t}}{\sigma-1}-\alpha \ln w_{t}^{S}+\ln A_{t}-\kappa
$$

where $\kappa \equiv \ln \left[\alpha^{-\alpha}(1-\alpha)^{-(1-\alpha)} \sigma /(\sigma-1)\right]$. Substituting (A.25) into (32), and using (A.26), social welfare can be written as

$$
W=f\left(\tau_{0}, \mu_{0}\right)+\sum_{t=1}^{\infty} \rho^{t}\left[\ln \left(1-\tau_{t}\right)+\frac{\ln n_{t}}{\sigma-1}-\alpha \ln w_{t}^{S}+\ln A_{t}-\kappa+F\left(\tilde{a}_{t}\right)\right],
$$

where

$$
F\left(\tilde{a}_{t}\right) \equiv \int_{\tilde{a}_{t}}^{1} \ln \left(a / \tilde{a}_{t}\right) d a
$$


Recall $\tau_{0}=\tilde{\tau}_{0}\left(G_{0}^{R}, G_{0}^{S}, \mu_{0}\right)$ and, for $t \geq 1, \tau_{t}=\tilde{\tau}\left(G_{t}^{R}, G_{t}^{S}, \mu_{t}\right)$, from (30) and (31), respectively. Thus, substituting (A.24), (22), (24), (26) and (27) into (A.27), observing (28), and making use of $\sum_{t=1}^{\infty} \rho^{t}=\rho /(1-\rho)$ and $\sum_{t=1}^{\infty} \rho^{t} t=\rho /(1-\rho)^{2}$, which are straightforward to verify, yields

$$
\begin{aligned}
W= & \text { const. }+f\left(\tilde{\tau}_{0}\left(G_{0}^{R}, G_{0}^{S}, \mu_{0}\right), \mu_{0}\right)+\rho\left(\gamma \beta^{R} \ln G_{0}^{R}+\alpha \beta^{S} \ln G_{0}^{S}\right)+ \\
& \frac{\rho}{1-\rho} Q\left(\bar{G}^{R}, \bar{G}^{S}, \bar{\mu}\right) \equiv W^{*}\left(G_{0}^{R}, G_{0}^{S}, \mu_{0}, \bar{G}^{R}, \bar{G}^{S}, \bar{\mu}\right)
\end{aligned}
$$

after some straightforward manipulations, where

$$
\begin{aligned}
Q\left(\bar{G}^{R}, \bar{G}^{S}, \bar{\mu}\right) \equiv & \ln \left(1-\tilde{\tau}\left(\bar{G}^{R}, \bar{G}^{S}, \bar{\mu}\right)\right)+\rho\left[\frac{(2-\rho) \gamma \beta^{R} \ln \bar{G}^{R}}{1-\rho}+\alpha \beta^{S} \ln \bar{G}^{S}\right]+ \\
& \left(\frac{1}{\sigma-1}+\frac{(1-\varepsilon) \rho}{1-\rho}-\alpha \beta^{S}\right) \ln a^{*}(\bar{\mu})+F\left(a^{*}(\bar{\mu})\right)+ \\
& \frac{\gamma}{1-\rho}\left[\ln \left(1+\frac{1}{a^{*}(\bar{\mu})}\right)+\left(1-\beta^{R}\right) \ln \left(1-a^{*}(\bar{\mu})\right)\right]
\end{aligned}
$$

Note that $W^{*}$ is strictly concave as function of $G_{0}^{k}, k=R, S$, and $\partial^{2} W^{*} / \partial G_{0}^{R} \partial G_{0}^{S}=$ 0 , according to (A.29), (30) and assumption $\partial^{2} f / \partial\left(\tau_{0}\right)^{2} \leq 0$. Similarly, note that $W^{*}$ is strictly concave as function of $\bar{G}^{k}, k=R, S$, and $\partial^{2} W^{*} / \partial \bar{G}^{R} \partial \bar{G}^{S}=0$, according to (A.30) and (31). A social planner maximizes $W^{*}(\cdot)$ with respect to $\left(G_{0}^{R}, G_{0}^{S}, \mu_{0}, \bar{G}^{R}, \bar{G}^{S}, \bar{\mu}\right)$. (Regarding $\mu_{0}$, the socially optimal solution has been discussed in the beginning of section 5.)

Next, verify from (A.28) that $F^{\prime}\left(\tilde{a}_{t}\right)=1-1 / \tilde{a}_{t}<0$. Thus, according to (A.30),

$$
\frac{\partial Q\left(\bar{G}^{R}, \bar{G}^{S}, \bar{\mu}\right)}{\partial \bar{\mu}}=-\frac{\partial \tilde{\tau} / \partial \bar{\mu}}{1-\tilde{\tau}}+\Lambda\left(a^{*}\right) \frac{\left(a^{*}\right)^{\prime}(\bar{\mu})}{a^{*}}
$$

where

$$
\Lambda\left(a^{*}\right) \equiv \frac{1}{\sigma-1}+\frac{(1-\varepsilon) \rho}{1-\rho}-\alpha \beta^{S}-\left(1-a^{*}\right)-\frac{\gamma}{1-\rho}\left[\frac{1}{a^{*}+1}+\frac{\left(1-\beta^{R}\right) a^{*}}{1-a^{*}}\right] .
$$

Note that $\partial \tilde{\tau} / \partial \bar{\mu}<0$ and $\left(a^{*}\right)^{\prime}(\bar{\mu})<0$, according to Lemma 3 and part (ii) of Propo- 
sition 2, respectively. Thus, according to (A.29) and (A.31), we have $\partial W^{*} / \partial \bar{\mu}<0$ for all $\bar{\mu} \in[0,1)$ if, for instance, $\Lambda\left(a^{*}(\bar{\mu})\right) \geq 0$ for all $\bar{\mu} \in[0,1)$. In this case, $\bar{\mu}=0$ is socially optimal. To confirm that $\bar{\mu}=0$ is possible in social optimum, and in particular if $\varepsilon=1$, the following numerical example is considered.

Suppose $\varepsilon=1, \alpha=\gamma=0.25, z^{R}=z^{S}=0.5, \rho=\beta^{R}=\beta^{S}=0.9$ and $\sigma=1.1$. Thus, $a^{*}(\bar{\mu})=\sqrt{(1-\bar{\mu}) /[0.4+1-\bar{\mu}]}$, according to (22), and $\bar{\mu} \in[0,1)$ implies $a^{*} \in(0, \sqrt{5 / 7}]$. Hence, $\bar{\mu}=0$ is socially optimal in this example, if $\Lambda\left(a^{*}\right) \geq 0$ for all $a^{*} \in(0, \sqrt{5 / 7}]$. According to (A.32), $\Lambda\left(a^{*}\right)=9.775-\left(1-a^{*}\right)-2.5 /\left(a^{*}+1\right)+$ $0.25 a^{*} /\left(1-a^{*}\right)$ in this numerical example. From this, it is easy to confirm that $\Lambda\left(a^{*}\right)>0$ for all $a^{*} \in(0, \sqrt{5 / 7}]$, which confirms that $\bar{\mu}=0$ is socially optimal.

For comparative-static results in Proposition 5, note that both $a^{*}$ and $\tilde{\tau}$ are independent of $\beta^{R}, \beta^{S}$ and $\varepsilon$, according to (22) and (31), respectively. Thus, recalling $a^{*}<1$ and $\left(a^{*}\right)^{\prime}(\bar{\mu})<0$, one obtains $\partial Q^{2} / \partial \bar{\mu} \partial v>0$ for $v=\beta^{S}, \varepsilon$ and $\partial Q^{2} / \partial \bar{\mu} \partial \beta^{R}<$ 0 , according to (A.31) and (A.32). This concludes the proof.

Proof of Proposition 6. Define $\varrho_{t} \equiv \gamma(\sigma-1) \mu_{t} /\left(1-\mu_{t}\right), t \geq 0$. Using (30) and (A.29), it is easy to verify that $\partial W^{*} / \partial G_{0}^{R}=\partial W^{*} / G_{0}^{S}=0$ implies

$$
\begin{aligned}
& \frac{\partial f\left(\frac{\Xi\left(G_{0}^{R}+G_{0}^{S}\right) / L_{0}^{U}+\varrho_{0}}{\sigma+\varrho_{0}}, \mu_{0}\right)}{\partial \tau_{0}} \frac{\Xi}{\left(\sigma+\varrho_{0}\right) L_{0}^{U}}+\frac{\rho \gamma \beta^{R}}{G_{0}^{R}}=0, \\
& \frac{\partial f\left(\frac{\Xi\left(G_{0}^{R}+G_{0}^{S}\right) / L_{0}^{U}+\varrho_{0}}{\sigma+\varrho_{0}}, \mu_{0}\right)}{\partial \tau_{0}} \frac{\Xi}{\left(\sigma+\varrho_{0}\right) L_{0}^{U}}+\frac{\rho \alpha \beta^{S}}{G_{0}^{S}}=0 .
\end{aligned}
$$

Recall $\partial^{2} f / \partial\left(\tau_{0}\right)^{2} \leq 0$ which implies that conditions (A.33) and (A.34) are sufficient to obtain the welfare-maximizing levels of $G_{0}^{R}$ and $G_{0}^{S}$ (given $\mu_{0}$ ). Thus, combining (A.33) and (A.34) confirms that $G_{0}^{R} / G_{0}^{S}=\gamma \beta^{R} /\left(\alpha \beta^{S}\right)$. Next, substitute $G_{0}^{S}=$ $G_{0}^{R} \alpha \beta^{S} /\left(\gamma \beta^{R}\right)$ into (A.33) and apply the implicit function theorem to confirm that $\partial G_{0}^{R} / \partial \beta^{R}>0, \partial G_{0}^{R} / \partial \beta^{S}<0$ and $\partial G_{0}^{R} / \partial v=0$ for $v=\varepsilon, \xi^{R}, \xi^{S}$. Comparativestatic results regarding $G_{0}^{S}$ can be derived analogously. Moreover, according to (31), (A.29) and (A.30), it is straightforward to show that $\partial W^{*} / \bar{G}^{R}=\partial W^{*} / \bar{G}^{S}=0$ 
implies

$$
\begin{aligned}
& \underbrace{\frac{\sigma-\frac{\Theta\left(\bar{G}^{R}+\bar{G}^{S}\right)}{L a^{*}\left(\mu_{t}\right)}}{\sigma+\varrho_{t}}}_{=1-\tilde{\tau}\left(\bar{G}^{R}, \bar{G}^{S}, \mu_{t}\right)} \frac{\rho(2-\rho) \gamma \beta^{R}}{(1-\rho) \bar{G}^{R}}=\frac{\Theta}{(\sigma+\bar{\varrho}) L a^{*}\left(\mu_{t}\right)}, \\
& \frac{\sigma-\frac{\Theta\left(\bar{G}^{R}+\bar{G}^{S}\right)}{L a^{*}\left(\mu_{t}\right)}}{\sigma+\varrho_{t}} \frac{\rho \alpha \beta^{S}}{\bar{G}^{S}}=\frac{\Theta}{(\sigma+\bar{\varrho}) L a^{*}\left(\mu_{t}\right)},
\end{aligned}
$$

which are sufficient optimality conditions (given $\mu_{t}=\bar{\mu}, t \geq 1$ ). Combining (A.35) and (A.36) confirms (33). Applying the implicit function theorem to (A.35) and (A.36), by using (33), confirms comparative-static results also for $t \geq 1$. This concludes the proof.

\section{References}

Aghion, Philippe and Peter Howitt (1992). A Model of Growth through Creative Destruction, Econometrica 60 (2), 323-351.

Alvarez-Pelaez, Maria J. and Christian Groth (2003). Too Little or Too Much R\&D?, European Economic Review (forthcoming).

Arnold, Lutz G. (1998). Growth, Welfare, and Trade in an Integrated Model of Human-Capital Accumulation and Research, Journal of Macroeconomics 20, 81-105.

COM (2003). Investing in Research: An Action Plan for Europe, Communication from the Commission of the European Communities 226, June 4, 2003.

De Hek, Paul A. (1999). On Endogenous Growth under Uncertainty, International Economic Review 40 (3), 727-44.

De Hek, Paul A. and Roy Santanu (2001). On Sustained Growth Under Uncertainty, International Economic Review 42 (3), 801-814.

Dinopoulos, Elias and Peter Thompson (1999). Scale Effects in Schumpeterian Models of Endogenous Growth, Journal of Evolutionary Economics 9, 155-185.

Dixit, Avinash and Joseph E. Stiglitz (1977). Monopolistic Competition and Optimum Product Diversity, American Economic Review 67, 297-308. 
European Commission (2003). Implementation of "Education \& Training 2010" Work Programme, Working Group: "Increasing Participation in Math, Sciences and Technology", Progress Report.

Funke, Michael and Holger Strulik (2000). On Endogenous Growth with Physical Capital, Human Capital and Product Variety, European Economic Review 44, 491515.

Galor, Oded and Omer Moav (2000). Ability-Biased Technological Transition, Wage Inequality, and Economic Growth, Quarterly Journal of Economics 115, 46997.

Glomm, Gerhard and B. Ravikumar (2003). Public Education and Income Inequality, European Journal of Political Economy 19 (2), 289-300

Goolsbee, Austan (1998). Does Government R\&D Policy Mainly Benefit Scientists and Engineers?, American Economic Review 88 (2), 298-302.

Grossman, Gene M. and Elhanan Helpman (1991). Quality Ladders in the Theory of Growth, Review of Economic Studies 58, 43-61.

Grossmann, Volker (2003). Contest for Attention in a Quality-Ladder Model of Endogenous Growth, CESifo Working Paper No. 1003.

Guellec, Dominique and Bruno van Pottelsberghe (2003). The Impact of Public R\&D Expenditure on Business R\&D, Economics of Innovation and New Technology $12(3), 225-243$.

Hall, Bronwyn and John van Reenen (2000). How Effective Are Fiscal Incentives for R\&D? A Review of the Evidence, Research Policy 29 (4-5), 449-469.

Jones, Charles I. (1995). Time Series Tests of Endogenous Growth Models, Quarterly Journal of Economics 110, 495-525.

Jones, Charles I. (1999). Growth: With or Without Scale Effects?, American Economic Review 89, 139-144.

Jones, Charles I. (2003). Growth and Ideas, in: Philippe Aghion and Steven Durlauf (Eds.), Handbook of Economic Growth, forthcoming.

Jones, Charles I. and John C. Williams (1998). Measuring the Social Return to R\&D, Quarterly Journal of Economics 113, 1119-1135. 
Jones, Charles I. and John C. Williams (2000). Too Much of a Good Thing? The Economics of Investment in R\&D, Journal of Economic Growth 5, 65-85.

Kremer, Michael (1993). Population Growth and Technological Change: One Million B.C. to 1990, Quarterly Journal of Economics 108, 681-716.

Murphy, Kevin M., Andrei Shleifer and Robert W. Vishny (1991). The Allocation of Talent: Implications for Growth, Quarterly Journal of Economics 106 (2), 503-530.

National Science Board (2002). Science and Engineering Indicators - 2002, Arlington, VA: National Science Foundation.

OECD (1999). Science, Technology and Industry Scoreboard 1999: Benchmarking Knowledge-based Economies, Paris.

Redding, Stephen (1996). The Low-skill, Low-quality Trap: Strategic Complementarities Between Human Capital and R\&D, Economic Journal 106, 458-470.

Romer, Paul (1990). Endogenous Technological Change, Journal of Political Economy 98 (5), S71-S102.

Romer, Paul (2000). Should the Government Subsidize Supply or Demand in the Market for Scientists and Engineers?, NBER Working Paper No. 7723.

Sapir, André, Philippe Aghion, Giuseppe Bertola, Martin Hellwig, Jean PisaniFerry, Dariusz Rosati and Helen Wallace (2004). An Agenda for a Growing Europe - The Sapir Report, Oxford University Press, Oxford.

Strulik, Holger (2004). The Role of Human Capital and Population Growth in R\&D-Based Models of Economic Growth, Review of International Economics, forthcoming.

Sutton, John (1998). Technology and Market Structure, MIT Press, Cambridge, MA.

Young, Alwyn (1998). Growth Without Scale Effects, Journal of Political Economy 106 (1), 41-63. 


\section{CESifo Working Paper Series}

(for full list see www.cesifo.de)

1160 Romain Ranciere, Aaron Tornell, and Frank Westermann, Crises and Growth: A ReEvaluation, March 2004

1161 Assaf Razin and Efraim Sadka, Transparency, Specialization and FDI, March 2004

1162 Ludger Woessmann, How Equal Are Educational Opportunities? Family Background and Student Achievement in Europe and the United States, March 2004

1163 B.M.S. van Praag and Barbara E. Baarsma, Using Happiness Surveys to Value Intangibles: The Case of Airport Noise, March 2004

1164 Aaron Tornell, Frank Westermann, and Lorenza Martínez, The Positive Link Between Financial Liberalization, Growth, and Crises, March 2004

1165 Helge Berger and Carsten Hefeker, One Country, One Vote? Labor Market Structure and Voting Rights in the ECB, March 2004

1166 Clemens Fuest and Martin Kolmar, A Theory of User-Fee Competition, March 2004

1167 Friedrich Schneider and Robert Klinglmair, Shadow Economies around the World: What Do We Know?, April 2004

1168 Horst Raff and Nicolas Schmitt, Exclusive Dealing and Common Agency in International Markets, April 2004

1169 M. Hashem Pesaran and Allan Timmermann, Real Time Econometrics, April 2004

1170 Sean D. Barrett, Privatisation in Ireland, April 2004

1171 V. Anton Muscatelli, Patrizio Tirelli and Carmine Trecroci, Can Fiscal Policy Help Macroeconomic Stabilisation? Evidence from a New Keynesian Model with Liquidity Constraints, April 2004

1172 Bernd Huber and Marco Runkel, Tax Competition, Excludable Public Goods and User Charges, April 2004

1173 John McMillan and Pablo Zoido, How to Subvert Democracy: Montesinos in Peru, April 2004

1174 Theo Eicher and Jong Woo Kang, Trade, Foreign Direct Investment or Acquisition: Optimal Entry Modes for Multinationals, April 2004

1175 Chang Woon Nam and Doina Maria Radulescu, Types of Tax Concessions for Attracting Foreign Direct Investment in Free Economic Zones, April 2004 
1176 M. Hashem Pesaran and Andreas Pick, Econometric Issues in the Analysis of Contagion, April 2004

1177 Steinar Holden and Fredrik Wulfsberg, Downward Nominal Wage Rigidity in Europe, April 2004

1178 Stefan Lachenmaier and Ludger Woessmann, Does Innovation Cause Exports? Evidence from Exogenous Innovation Impulses and Obstacles, April 2004

1179 Thiess Buettner and Johannes Rincke, Labor Market Effects of Economic Integration The Impact of Re-Unification in German Border Regions, April 2004

1180 Marko Koethenbuerger, Leviathans, Federal Transfers, and the Cartelization Hypothesis, April 2004

1181 Michael Hoel, Tor Iversen, Tore Nilssen, and Jon Vislie, Genetic Testing and Repulsion from Chance, April 2004

1182 Paul De Grauwe and Gunther Schnabl, Exchange Rate Regimes and Macroeconomic Stability in Central and Eastern Europe, April 2004

1183 Arjan M. Lejour and Ruud A. de Mooij, Turkish Delight - Does Turkey's accession to the EU bring economic benefits?, May 2004

1184 Anzelika Zaiceva, Implications of EU Accession for International Migration: An Assessment of Potential Migration Pressure, May 2004

1185 Udo Kreickemeier, Fair Wages and Human Capital Accumulation in a Global Economy, May 2004

1186 Jean-Pierre Ponssard, Rent Dissipation in Repeated Entry Games: Some New Results, May 2004

1187 Pablo Arocena, Privatisation Policy in Spain: Stuck Between Liberalisation and the Protection of Nationals' Interests, May 2004

1188 Günter Knieps, Privatisation of Network Industries in Germany: A Disaggregated Approach, May 2004

1189 Robert J. Gary-Bobo and Alain Trannoy, Efficient Tuition Fees, Examinations, and Subsidies, May 2004

1190 Saku Aura and Gregory D. Hess, What's in a Name?, May 2004

1191 Sjur Didrik Flåm and Yuri Ermoliev, Investment Uncertainty, and Production Games, May 2004

1192 Yin-Wong Cheung and Jude Yuen, The Suitability of a Greater China Currency Union, May 2004 
1193 Inés Macho-Stadler and David Pérez-Castrillo, Optimal Enforcement Policy and Firms' Emissions and Compliance with Environmental Taxes, May 2004

1194 Paul De Grauwe and Marianna Grimaldi, Bubbles and Crashes in a Behavioural Finance Model, May 2004

1195 Michel Berne and Gérard Pogorel, Privatization Experiences in France, May 2004

1196 Andrea Galeotti and José Luis Moraga-González, A Model of Strategic Targeted Advertising, May 2004

1197 Hans Gersbach and Hans Haller, When Inefficiency Begets Efficiency, May 2004

1198 Saku Aura, Estate and Capital Gains Taxation: Efficiency and Political Economy Consideration, May 2004

1199 Sandra Waller and Jakob de Haan, Credibility and Transparency of Central Banks: New Results Based on Ifo's World Economicy Survey, May 2004

1200 Henk C. Kranendonk, Jan Bonenkamp, and Johan P. Verbruggen, A Leading Indicator for the Dutch Economy - Methodological and Empirical Revision of the CPB System, May 2004

1201 Michael Ehrmann, Firm Size and Monetary Policy Transmission - Evidence from German Business Survey Data, May 2004

1202 Thomas A. Knetsch, Evaluating the German Inventory Cycle - Using Data from the Ifo Business Survey, May 2004

1203 Stefan Mittnik and Peter Zadrozny, Forecasting Quarterly German GDP at Monthly Intervals Using Monthly IFO Business Conditions Data, May 2004

1204 Elmer Sterken, The Role of the IFO Business Climate Indicator and Asset Prices in German Monetary Policy, May 2004

1205 Jan Jacobs and Jan-Egbert Sturm, Do Ifo Indicators Help Explain Revisions in German Industrial Production?, May 2004

1206 Ulrich Woitek, Real Wages and Business Cycle Asymmetries, May 2004

1207 Burkhard Heer and Alfred Maußner, Computation of Business Cycle Models: A Comparison of Numerical Methods, June 2004

1208 Costas Hadjiyiannis, Panos Hatzipanayotou, and Michael S. Michael, Pollution and Capital Tax Competition within a Regional Block, June 2004

1209 Stephan Klasen and Thorsten Nestmann, Population, Population Density, and Technological Change, June 2004

1210 Wolfgang Ochel, Welfare Time Limits in the United States - Experiences with a New Welfare-to-Work Approach, June 2004 
1211 Luis H. R. Alvarez and Erkki Koskela, Taxation and Rotation Age under Stochastic Forest Stand Value, June 2004

1212 Bernard M. S. van Praag, The Connexion Between Old and New Approaches to Financial Satisfaction, June 2004

1213 Hendrik Hakenes and Martin Peitz, Selling Reputation When Going out of Business, June 2004

1214 Heikki Oksanen, Public Pensions in the National Accounts and Public Finance Targets, June 2004

1215 Ernst Fehr, Alexander Klein, and Klaus M. Schmidt, Contracts, Fairness, and Incentives, June 2004

1216 Amihai Glazer, Vesa Kanniainen, and Panu Poutvaara, Initial Luck, Status-Seeking and Snowballs Lead to Corporate Success and Failure, June 2004

1217 Bum J. Kim and Harris Schlesinger, Adverse Selection in an Insurance Market with Government-Guaranteed Subsistence Levels, June 2004

1218 Armin Falk, Charitable Giving as a Gift Exchange - Evidence from a Field Experiment, June 2004

1219 Rainer Niemann, Asymmetric Taxation and Cross-Border Investment Decisions, June 2004

1220 Christian Holzner, Volker Meier, and Martin Werding, Time Limits on Welfare Use under Involuntary Unemployment, June 2004

1221 Michiel Evers, Ruud A. de Mooij, and Herman R. J. Vollebergh, Tax Competition under Minimum Rates: The Case of European Diesel Excises, June 2004

1222 S. Brock Blomberg and Gregory D. Hess, How Much Does Violence Tax Trade?, June 2004

1223 Josse Delfgaauw and Robert Dur, Incentives and Workers' Motivation in the Public Sector, June 2004

1224 Paul De Grauwe and Cláudia Costa Storti, The Effects of Monetary Policy: A MetaAnalysis, June 2004

1225 Volker Grossmann, How to Promote R\&D-based Growth? Public Education Expenditure on Scientists and Engineers versus R\&D Subsidies, June 2004 